\title{
Oil shocks and stock markets: Dynamic connectedness under the prism of recent geopolitical and economic unrest
}

\author{
Nikolaos Antonakakis ${ }^{\mathrm{a}, \mathrm{b}, \mathrm{c}, *}$, Ioannis Chatziantoniou ${ }^{\mathrm{b}}$, George Filis ${ }^{\mathrm{d}, \mathrm{e}}$ \\ ${ }^{a}$ Webster Vienna Private University, Department of Business and Management, Praterstrasse 23, 1020, \\ Vienna, Austria. \\ ${ }^{b}$ University of Portsmouth, Department of Economics and Finance, Portsmouth Business School, Portland \\ Street, Portsmouth, PO1 3DE, United Kingdom \\ ' Johannes Kepler University, Department of Economics, Altenberger Strasse 69, 4040 Linz-Auhof, Austria. \\ ${ }^{d}$ Bournemouth University, Department of Accounting, Finance and Economics, 89 Holdenhurst Road, \\ Bournemouth, Dorset, BH8 8EB, United Kingdom \\ ${ }^{e}$ Surrey Energy Economics Centre (SEEC), Faculty of Economics Business and Law, School of Economics, \\ University of Surrey, Guildford, GU2 7XH, United Kingdom
}

\begin{abstract}
In this study we examine the dynamic structural relationship between oil price shocks and stock market returns or volatility for a sample of both net oil-exporting and net oil-importing countries between 1995:09 and 2013:07. We accomplish that, by extending the Diebold and Yilmaz (2014) dynamic connectedness measure using structural forecast error variance decomposition. The results for both stock market returns and volatility suggest that connectedness varies across different time periods, and that this time-varying character is aligned with certain developments that take place in the global economy. In particular, aggregate demand shocks appear to act as the main transmitters of shocks to stock markets during periods characterised by economic-driven events, while supply-side and oil-specific demand shocks during periods of geopolitical unrest. Furthermore, differences regarding the directions and the strength of connectedness can be reported both between and within the net oil-importing and net oil-exporting countries. These results are of particular importance to investors and portfolio managers, given the recent financialisation of the oil market.
\end{abstract}

Keywords: Oil price shocks, Stock market, Connectedness, Structural Vector Autoregression, Geopolitical unrest, Economic crisis

JEL codes: C32; C51; G11; G15; Q41; Q43

\footnotetext{
*Corresponding author, email: nikolaos.antonakakis@webster.ac.at, phone: +43-1-269 92 93-4354.

Email addresses: nikolaos.antonakakis@webster.ac.at, nikolaos.antonakakis@port.ac.uk (Nikolaos Antonakakis), ioannis.chatziantoniou@port.ac.uk (Ioannis Chatziantoniou), gfilis@bournemouth.ac.uk (George Filis)
} 


\section{Introduction}

The aim of this paper is to investigate the dynamic structural connectedness between oil price shocks and stock market returns and volatility of 11 major stock markets around the world (considering both net oil-importing and net oil-exporting countries), for the period September 1995 to July 2013.

The investigation of the time-varying connectedness between oil price shocks and stock market activity is important given the recent geopolitical unrest and the financialisation of the oil market. According to Büyükşahin and Robe (2014), Hamilton and Wu (2014), Alquist and Kilian (2010) and Fattouh (2010), investors and portfolio managers have increased their positions in the oil market over the last decade or so. Authors, such as, Hamilton and Wu (2014); Morana (2013); Fattouh et al. (2013); Alquist and Kilian (2010) claim that increased speculative activity is observed in the oil market due to its financialisation, which leads the stock and oil markets to exhibit a higher interdependence. Furthermore, events such as the Arab Spring, the political turbulence and war conflicts in Yemen, Bahrain and Egypt or even the Syrian civil war have resulted in substantial oil price swings, which spark uncertainty in financial markets.

In this respect, it is important to identify, for the first time, the time-varying spillover effects between oil and stock markets and to analyse these effects under the prism of the aforementioned recent geopolitical and economic unrest. Such approach is useful to market participants making decisions about portfolio adjustments, asset pricing, as well as, the development of models for forecasting.

We highlight that the issue of interdependence (either in a static or a time-varying environment) between financial markets and its importance for portfolio managers, asset pricing model and forecasting has been extensively studied in the literature (see, for instance Apergis et al., 2016; Baruník et al., 2016; Yarovaya et al., 2016; Barunik and Krehlik, 2015; Alter and Beyer, 2014; Claeys and Vašíček, 2014; Jiang et al., 2012; Alter and Schüler, 2012; Antonakakis, 2012; Bubák et al., 2011; McMillan and Speight, 2010). Nevertheless, the literature on the examination of the time-varying interdependence between oil and stock markets is still growing, whereas this is the first effort to investigate the time-varying spillover effects between oil shocks and stock markets.

Our study builds upon the study of Awartani and Maghyereh (2013), which also employs the Diebold and Yilmaz (2012) methodology. Nevertheless, their study investigates the spillover effects between GCC stock markets and oil prices, whereas in our study we disentangle oil prices into three oil price shocks by virtue of their origin (i.e. supply-side, aggregate demand and oil specific demand shocks). As primarily shown by Kilian and Park (2009), disentangling oil price shocks allows us to understand better the effects of oil on the financial markets.

To do so, we extend the Diebold and Yilmaz (2014) connectedness measure in the following way. Instead of using a generalized vector autoregressive framework in which forecasterror variance decompositions are invariant to the variable ordering, we propose a structural vector autoregressive framework that allows for the identification of the supply-side, aggregate demand and oil-specific demand oil market shocks. 
Even more, this study distinguishes between oil-importing and oil-exporting countries, given the increasing evidence that the effects of oil price changes on stock market performance are different for oil-importers and oil-exporters. More specifically, oil price increases are considered as negative news for oil-importing economies, given that the former leads to higher production costs for the domestic firms, which subsequently leads to higher prices and lower consumption. The end result is that there are lower cash flows at firm level and thus lower stock prices (see, inter alia, Jones et al., 2004; Brown and Yucel, 1999; Hamilton, 1996). By contrast, higher oil prices are expected to increase the income and wealth of the oil-exporting economies, leading to higher economic activity and thus higher firm-level cash flows. Stock markets in these countries are expected to react positively to these developments (see, for instance, Wang et al., 2013; Arouri et al., 2012; Bjørnland, 2009). Thus, we maintain, that oil prices shocks are anticipated to cause heterogeneous responses from the stock markets, depending on whether these operate in oil-importing or oil-exporting economies.

The findings of the study stress the necessity to investigate the connectedness of oil prices and the stock market both over time and by disentangling oil price shocks by virtue of their origin. In particular, we show that connectedness varies across different time periods and that this time-varying character is aligned with certain developments that take place in the global economy. In this regard, aggregate demand shocks appear to act as the main source of connectedness shocks to stock markets during periods of economic and financial uncertainty, while supply-side and oil-specific demand shocks during periods of geopolitical unrest.

On a secondary level, we provide evidence that differences regarding the direction and the strength of the connectedness can be found both between and among the two groups of countries under investigation (i.e. net oil-importing and net oil-exporting countries) emphasizing the fact that these differences mainly pertain to the time-varying character of the relationship between oil prices and the stock market. On a final note, our results do not indicate any notable differences between current-looking and forward-looking measures of stock market volatility.

The remainder of the paper is organized as follows. Section 2 presents a brief overview of the literature review and discusses the contributions of the paper. Section 3 discusses the methodology and describes the data. Section 4 presents the empirical findings, while Section 5 provides an in-depth discussion of the findings. Finally, Section 6 summarises and concludes the paper.

\section{Brief review of the literature and contribution}

Since the seminal paper by Jones and Kaul (1996) there is an ever increasing interest to understand the effects of oil prices on stock markets (some recent studies include those by Filis and Chatziantoniou, 2014; Asteriou and Bashmakova, 2013; Ciner, 2013; Lee and Chiou, 2011; Laopodis, 2011; Narayan and Sharma, 2011; Filis, 2010; Chen, 2010; Miller and Ratti, 2009). In recent years though, the literature has directed its attention to three different strands. 
The first strand is related to the origin of oil price changes; that is, to whether oil prices change due to supply-driven or demand-driven events. Pioneers in this line of inquiry are Hamilton (2009a,b) and Kilian (2009) who, on general principles, argue that different oil price shocks should trigger different responses from economic indicators and stock markets. More specifically, Hamilton (2009a,b) classifies oil price changes (shocks) into supply-side and demand-side shocks, depending on whether these can be attributed to changes in global oil production or changes in global aggregate demand, respectively. Hamilton (2009a,b) maintains that supply-side shocks are related to disruption in the oil supply, primarily due to geopolitical unrest in the Middle East. On the other hand, demand-side shocks are related to the global business cycle, suggesting that during recessions the demand for oil decreases leading its price to fall and vice versa. Kilian (2009) further classifies demandside shocks into aggregate demand shocks - which have their origin in changes in global aggregate demand (similarly to Hamilton $(2009 a, b))$ - and precautionary demand shocks (or oil specific demand shocks). The latter shocks pertain to the uncertainty about the future availability of oil, which reflects expectations about the future supply of oil. These expectations are formed in response to geopolitical events, primarily in the Middle East. Thus, geopolitical events, such as the Arab Spring, instantly increases the precautionary demand for oil, given that economic agents form the belief that there will be shortage in oil supply in the future as a result of these events. According to Kilian (2009), it is the precautionary demand shocks which are primarily related to geopolitical turbulence, rather than the physical disruption of oil supply (i.e. the supply-side shocks).

The findings by Hamilton (2009a,b) and Kilian (2009) suggest that, aggregate demand shocks trigger positive responses from the economy, whereas the opposite holds for precautionary demand shocks. On the other hand, supply-side shocks are significantly less important for the economy. A wealth of literature supports the findings reported by Hamilton (2009a,b) and Kilian (2009) and thus providing ample evidence suggesting that supply-side shocks do not seem to affect financial markets, whereas positive aggregate demand shocks (precautionary shocks) exert a positive (negative) impact (see, inter alia, Degiannakis et al., 2014; Abhyankar et al., 2013; Kang and Ratti, 2013; Baumeister and Peersman, 2013; Kilian and Park, 2009; Apergis and Miller, 2009).

The second and rather recent strand in the literature focuses on the time-varying relationship between oil prices and stock markets. Authors, such as, Sadorsky (2014), Broadstock and Filis (2014), Filis (2014), Chang et al. (2013), Antonakakis and Filis (2013), Sadorsky (2012), Broadstock et al. (2012), Filis et al. (2011) and Choi and Hammoudeh (2010), subscribe to the belief that the relationship between oil and stock markets should not be examined within a static framework but rather in a time-varying one, given that the nature of this relationship changes at different points in time. Indicatively, Chang et al. (2013) focusing on the US and the UK markets, show an increase in the correlation between oil and stock market returns in the post-2008 period. Similar findings are reported by Sadorsky (2014) for various emerging stock markets. Furthermore, Broadstock et al. (2012) also provide evidence that the correlation between energy-related stock returns and changes in oil prices exhibits a significant increase during the period of the Great Recession.

The third strand is associated with the spillover effects between the two markets under 
consideration. This line of research purports to identify whether there are any volatility spillovers between oil and stock markets, as well as, the direction of these spillovers (see, among others, Chang et al., 2013; Mensi et al., 2013; Arouri et al., 2012, 2011a,b; Malik and Ewing, 2009; Malik and Hammoudeh, 2007). To illustrate this, Mensi et al. (2013) and Arouri et al. (2012) find significant volatility spillover effects between the oil market and the US or the European stock markets, respectively. However, Mensi et al. (2013) suggest that spillovers run from the S\&P500 to the oil market, while Arouri et al. (2012) report that the reverse is true for the case of the European stock market. Arouri et al. (2011b) provide further evidence regarding the significant increase of the volatility spillover effects during the global financial crisis. By contrast, Chang et al. (2013) do not report any volatility spillover effects between the oil market and key global stock market indices (FTSE100, Dow Jones, NYSE and S\&P500).

This paper brings together the three aforementioned strands of existing literature. In particular, we examine the time-varying effects between oil price shocks and stock market returns, as well as the time-varying effects between oil price shocks and stock market volatility - by considering two current-looking measures of volatility (i.e. conditional and realised volatility) and one forward-looking measure (i.e. implied volatility). It should be noted that the implied volatility measure is mainly introduced to the analysis for robustness purposes. Furthermore, much of the analysis in the existing literature does not focus on the various geopolitical effects that might influence the relationship between oil price shocks and stock market performance. In our study, we focus on both geopolitical and economic events, as potential drivers of the time-varying spillover effects between the aforementioned markets.

Finally, the majority of the aforementioned studies utilise either a Structural Vector Autoregressive (SVAR) model, when focusing on the effects of oil price shocks or a multivariate GARCH model, when investigating the time-varying correlations and spillover effects. Our study extends the newly introduced Diebold and Yilmaz (2014) connectedness measure, where, instead of using a generalized vector autoregressive framework, we propose a SVAR framework, which allows for the identification of the supply-side, aggregate demand and oil-specific demand oil market shocks. Thus, we maintain that our study does not merely link the three aforementioned strands of the literature but it also uses existing econometric methods (i.e. SVAR) to extend the current models for measuring spillover effects (i.e. the Diebold and Yilmaz (2014) connectedness measure).

\section{Methodology and Data}

\subsection{The connectedness measure methodology}

The connectedness measure introduced by Diebold and Yilmaz (2014) builds on the Diebold and Yilmaz $(2009,2012)$ spillover index approach and on the seminal work on VAR models by Sims (1980) with the well-known notion of variance decompositions. It allows an assessment of the contributions of shocks to variables to the forecast error variances of both the respective and the other variables of the model. Using rolling-window estimation, the evolution of the connectedness measure can be traced over time and illustrated by connectedness plots. 
However, a key methodological innovation and contribution of this study is that, instead of using the generalised vector autoregressive framework, we adopt a structural vector autoregressive framework, as it allows for the identification of the oil price shocks. Thus, the choice of structural variance decomposition is predicated upon our empirical exercise. That is, to examine the effects of oil price shocks on stock market returns and volatility. In particular, we disaggregate oil price shocks based on the framework of Kilian and Park (2009). Essentially, with the use of a SVAR model, we distinguish between three types of oil price shocks; namely, supply-side shocks (SS), aggregate demand demand (ADS), as well as, oil specific demand shocks (OSS); and by including stock market returns (volatility) in the SVAR, we assess the effects of oil price shocks on stock market returns (volatility).

For the general case of a $p^{t h}$-order Structural VAR model, we obtain the following standard representation:

$$
\mathbf{A}_{0} \mathbf{y}_{t}=\mathbf{c}_{0}+\sum_{i=1}^{p} \mathbf{A}_{i} \mathbf{y}_{t-i}+\varepsilon_{t}
$$

where, $\mathbf{y}_{t}$ is a $[N \times 1]$ vector of endogenous variables. In this paper, $N=4$, containing world oil production, the global economic activity index, real oil price returns and the stock market returns (volatility) of the respective country, noting that the order of the variables is important. $A_{0}$ represents the $[N \times N]$ contemporaneous matrix, $A_{i}$ are $[N \times N]$ autoregressive coefficient matrices, $\varepsilon_{t}$ is a $[N \times 1]$ vector of structural disturbances, assumed to have zero covariance and be serially uncorrelated. The covariance matrix of the structural disturbances takes the following form:

$$
E\left[\varepsilon_{t} \varepsilon_{t}^{\prime}\right]=\mathbf{D}=\left[\begin{array}{cccc}
\sigma_{1}^{2} & 0 & 0 & 0 \\
0 & \sigma_{2}^{2} & 0 & 0 \\
0 & 0 & \sigma_{3}^{2} & 0 \\
0 & 0 & 0 & \sigma_{4}^{2}
\end{array}\right]
$$

In order to get the reduced form of our structural model (1) we multiply both sides with $\mathbf{A}_{0}^{-1}$, such as that:

$$
\mathbf{y}_{t}=\mathbf{a}_{0}+\sum_{i=1}^{p} \mathbf{B}_{i} \mathbf{y}_{t-i}+\mathbf{e}_{t}
$$

where $\mathbf{a}_{0}=\mathbf{A}_{0}^{-1} \mathbf{c}_{0}, \mathbf{B}_{i}=\mathbf{A}_{0}^{-1} \mathbf{A}_{i}$, and $\mathbf{e}_{t}=\mathbf{A}_{0}^{-1} \varepsilon_{t}$, i.e. $\varepsilon_{t}=\mathbf{A}_{0} \mathbf{e}_{t}$. The reduced form errors $\mathbf{e}_{t}$ are linear combinations of the structural errors $\mathbf{e}_{t}$, with a covariance matrix of the form $E\left[\mathbf{e}_{t} \mathbf{e}_{t}^{\prime}\right]=\mathbf{A}_{0}^{-1} \mathbf{D} \mathbf{A}_{0}^{-1^{\prime}}$.

Imposing suitable restrictions on $\mathbf{A}_{0}^{-1}$ allows us to identify the structural disturbances of the model. In particular, we impose the following short-run restrictions:

$$
\left[\begin{array}{c}
e_{1, t}^{\Delta \text { Oil Production }} \\
e_{2, t}^{\text {Real Global Economic Activity }} \\
e_{3, t}^{\Delta \text { Real Oil Prices }} \\
\text { Stock Market Returns (Volatility) }
\end{array}\right]=\left[\begin{array}{cccc}
\alpha_{11} & 0 & 0 & 0 \\
\alpha_{21} & \alpha_{22} & 0 & 0 \\
\alpha_{31} & \alpha_{32} & \alpha_{33} & 0 \\
\alpha_{41} & \alpha_{42} & \alpha_{43} & \alpha_{44}
\end{array}\right] \times\left[\begin{array}{c}
\varepsilon_{1, t}^{S S} \\
\varepsilon_{2, t}^{A D S} \\
\varepsilon_{3, t}^{O S S} \\
\varepsilon_{4, t}^{S M R(S M V)}
\end{array}\right]
$$

where $S S$ is the supply-side shock, $A D S$ is the aggregate demand shock, $O S S$ is the oil specific demand shock, and $S M R(S M V)$ is the stock market returns (volatility) shock. 
The purpose of the short-run restrictions we impose on the model is to help us identify the underlying oil price shocks, as it has been established by Kilian and Park (2009). According to the restrictions for $N=4$, high adjustment costs forbid oil production to contemporaneously respond to changes in demand for oil. Furthermore, changes in the supply of oil are allowed to contemporaneously affect both global economic activity and the price of oil. In addition, given that it takes some time for the global economy to react to changes in the price of oil, global economic activity is assumed not to receive contemporaneous feedback from oil prices. However, changes in aggregate economic activity is expected to have a contemporaneous impact on oil prices and this is largely explained by the instantaneous response of commodities markets. Furthermore, it is understandable that oil price developments can be triggered by all types of shocks and in this regard all types of shocks are assumed to contemporaneously affect oil prices. Finally, stock market returns (volatility) respond contemporaneously to all aforementioned oil price shocks.

We should reiterate here that disentangling oil price changes into these three shocks is of major importance, as the literature has convincingly shown that the different oil shocks are related to geopolitical events (i.e. supply-side and precautionary demand) and economic developments (i.e. aggregate demand shocks.)

Key to the dynamics of the system is the moving average representation of model (3), which is given by $\mathbf{y}_{t}=\mathbf{C}(L)^{-1} \varepsilon_{t}$, where by definition $\varepsilon_{t}=\mathbf{C}_{\mathbf{0}}{ }^{-1} u_{t}$ and $\sum_{\varepsilon}=\mathbf{C}_{\mathbf{0}}{ }^{-1} \mathbf{C}_{\mathbf{0}}{ }^{-1^{\prime}}$.

Diebold and Yilmaz (2009) use Cholesky decomposition, which yields variance decompositions dependent on the ordering of the variables, whereas Diebold and Yilmaz $(2012,2014)$ extend the Diebold and Yilmaz (2009) model, using the generalized VAR framework of Koop et al. (1996) and Pesaran and Shin (1998), in which variance decompositions are invariant to the order of the variables. In this study, however, we use structural identification. All the aforementioned models (including ours) yield an $N \times N$ matrix $\phi(H)=\left[\phi_{i j}(H)\right]_{i, j=1, \ldots N}$, where each entry gives the contribution of shock associated with variable $j$ to the forecast error variance of variable $i$. The main diagonal elements contain the (own) contributions of shocks to the variable $i$ to its own forecast error variance, the off-diagonal elements show the (cross) contributions of the other variables $j$ to the forecast error variance of variable $i$.

This ultimately allows to define a total connectedness measure, which is given by

$$
T S(H)=\frac{\sum_{i, j=1, i \neq j}^{N} \phi_{i j}(H)}{\sum_{i, j=1}^{N} \phi_{i j}(H)} \times 100=\frac{\sum_{i, j=1, i \neq j}^{N} \phi_{i j}(H)}{N} \times 100
$$

which gives the average connectedness due to shocks to all (other) variables to the total forecast error variance.

This approach is quite flexible and allows to obtain a more differentiated picture by considering the gross directional connectedness: Specifically, the gross directional connectedness to variable $i$ from all other variables $j$ are defined as

$$
D S_{i \leftarrow j}(H)=\frac{\sum_{j=1, j \neq i}^{N} \phi_{i j}(H)}{\sum_{i, j=1}^{N} \phi_{i j}(H)} \times 100=\frac{\sum_{j=1, j \neq i}^{N} \phi_{i j}(H)}{N} \times 100
$$


and the gross directional connectedness from variable $i$ to all other variables $j$ as

$$
D S_{i \rightarrow j}(H)=\frac{\sum_{j=1, j \neq i}^{N} \phi_{j i}(H)}{\sum_{i, j=1}^{N} \phi_{j i}(H)} \times 100=\frac{\sum_{j=1, j \neq i}^{N} \phi_{j i}(H)}{N} \times 100 .
$$

Notice that the set of gross directional connectedness measures provide a decomposition of total connectedness into those coming from (or to) a particular source.

By subtracting Equation (6) from Equation (7) the net directional connectedness from variable $i$ to all other variables $j$ are obtained as

$$
N S_{i}(H)=D S_{i \rightarrow j}(H)-D S_{i \leftarrow j}(H),
$$

providing information on whether a variable is a receiver or transmitter of shocks in net terms. Put differently, Equation (8) provides summary information about how much each variable contributes to the volatility (or returns) in other variables, in net terms.

Finally, the net pairwise directional connectedness can be calculated as

$$
\begin{aligned}
N P S_{i j}(H) & =\left(\frac{\phi_{j i}(H)}{\sum_{i, m=1}^{N} \phi_{i m}(H)}-\frac{\phi_{i j}(H)}{\sum_{j, m=1}^{N} \phi_{j m}(H)}\right) \times 100 \\
& =\left(\frac{\phi_{j i}(H)-\phi_{i j}(H)}{N}\right) \times 100 .
\end{aligned}
$$

The net pairwise directional connectedness measure between variables $i$ and $j$ is simply the difference between the gross directional connectedness transmitted from variable $i$ to variable $j$ and those transmitted from $j$ to $i$.

The connectedness measure provides measures of the intensity of interdependence across countries and variables and allows a decomposition of the connectedness by source and recipient.

\subsection{Data description}

We collect monthly data of stock market indices for major oil-importing and oil- exporting countries, namely, Canada (S\&P/TSX), China (SSE), ESP (IBEX35), France (CAC40), Germany (DAX30), Italy (FTSEITA), Japan (NIKKEI225), Norway (OSE), Russia (RTS) the UK (FTSE100) and the US (S\&P500) from Datastream. The stock market indices series are converted into real stock market returns using the first difference of the natural logarithms of CPI deflated stock market indices. The motivation for the choice of these countries stems from the literature. Specifically, empirical evidence shows that the impact of oil price changes (shocks) on a particular stock market depends on whether the country, that the market is operating in, is a net oil-importer or a net oil-exporter. For instance, Wang et al. (2013); Mohanty et al. (2011); Bjørnland (2009) claim that positive oil prices changes trigger positive responses for the stock markets of net oil-exporting countries, whereas the opposite stands true for the stock markets of the net oil-importers. Thus, in order to capture any possible heterogenous behaviour, our sample consists of the main net oil-importers and net oil-exporters of the world. In addition, we collect monthly data for oil prices, world 
oil production and the real global economic activity index (GEA), which are used for the estimation of the oil price shocks. Data for the Brent crude oil price and world oil production have been extracted from the Energy Information Administration, whereas the data for the real global economic activity index have been retrieved from Lutz Kilian's personal website (http://www-personal.umich.edu/ lkilian/). The time period of study runs from 1995:09 until 2013:07. Real oil prices and real world oil production are transformed to stationary series by taking the first differences of natural logarithms. Table 1 reports the descriptive statistics of the series.

\section{[Insert Table 1 around here]}

According to Table 1, all stock markets returns are positive on average, apart from Japan, where negative returns are recorded. Stock market returns exhibit some variability, as shown by the standard deviation, the minimum and the maximum values. In particular, stock market returns in Russia are the most volatile, while stock market returns in the US are the least volatile. With regard to oil price changes, we observe a positive mean value, with quite a high standard deviation. In addition, none of the series is normally distributed, as indicated by the skewness, kurtosis and the Jarque-Bera statistic. Finally, according to the ADF-statistic, all variables are stationary.

Figures 1 and 2 exhibit the evolution of the series during the sample period. On general principles, we notice that negative economic events result in lower stock market returns on one hand and in higher stock market volatility on the other. This finding resonates with authors such as Bloom (2009) and Baker et al. (2016) who report that major shocks tend to increase uncertainty in the economy, which in turn, affects many aspects of real economic activity such as stock markets, firm and industry-level earnings, output productivity, as well as employment. A stellar example of this is the Great Recession of 2007-2009. As evident in Figures 1 and 2, during the years of the Great Recession, low returns and high volatility were in fact a common feature in all stock markets.

Figures 1 and 2 exhibit the evolution of the series during the sample period. All stock market returns exhibit some common troughs. To be more explicit, in all markets we notice the significant negative impact of the Great Recession of 2007-2009. In addition, we observe that for most European stock markets, a second important trough is observed during the first few months of the European debt crisis in 2010. Furthermore, stock market volatilities also exhibit common patterns. More importantly, we observe the peak of volatility during the period 2007-2009, signifying the turmoil that the Great Recession brought to these markets. However, a second peak in the European stock market volatilities is noticed during the early stages of the ongoing European debt crisis. Finally, the effects of the Great Recession are also evident on the changes of oil production, global economic activity, as well as, on oil price changes, where a significant decline is observed.

[Insert Figure 1 around here]

[Insert Figure 2 around here] 


\section{Empirical Results}

\subsection{Oil price shocks and stock market returns}

\subsubsection{Total connectedness measure between oil price shocks and stock market returns}

The total connectedness measure between stock market returns and disaggregated oil price shocks within countries are presented in Table 2. ${ }^{1}$ According to these results we observe that on average the total connectedness measures range between $18.7 \%$ (UK) and $25.8 \%$ (Norway), indicating a moderate interdependence between oil market shocks and stock market returns for most countries. On average, we show that net directional connectedness for the whole sample is taken over from the stock market returns in Canada, China, Spain, Germany, Japan, Norway and in Russia, while in France, Italy, the UK and the US, stock market returns act as net receivers from oil price shocks (see, Table 2). Among oil price shocks, aggregate demand shocks are generally net transmitters of shocks (with the exception of China and Russia), while supply-side shocks and oil-specific demand shocks are generally on the receiving ends (with the exception of Germany, Italy, Norway and the UK in terms of the former shocks, and of Canada and Spain in terms of the latter shocks). These results are in line with the literature that emphasises the importance of demand-side shocks, as opposed to supply-side shocks (see, among others, Baumeister and Peersman, 2013; Lippi and Nobili, 2012; Hamilton, 2009a,b).

\section{[Insert Table 2 around here]}

Despite the fact that Table 2 reveals some interesting patterns on the link between oil price shocks and stock market returns, we should not lose sight of the fact that during our sample period several economic, financial and geopolitical events took place, which impacted both the oil and the stock markets (e.g. the dot-com bubble in early the2000s, the war in Iraq in 2003, the Great Recession of 2007-2009, the ongoing European debt crisis of 2010 and Arab uprising which began in 2010 and was subsequently succeeded by a series of geopolitical events such as the Libyan civil war in 2011 and the Syrian unrest of 2013). Hence, the average values presented in Table 2 are not expected to hold for the whole time span. Thus, it would be valuable to examine how these connectedness measures evolve over time. Therefore we proceed with our analysis by presenting the total and net directional connectedness using $60-$ month rolling window analysis. ${ }^{2}$

\footnotetext{
${ }^{1}$ The Akaike Information Criterion (AIC) suggested 2 lags to be included in the SVAR specification. Given that we do not use the oil price in levels but rather in returns, we do not need to have 24 lags, as in Kilian and Park (2009). We have also explored the robustness of our results displayed below by increasing the number of lags up to 4 and our results remained qualitatively similar. These results are available upon request.

${ }^{2}$ It should be underlined that different forecast horizons (from 5 up to 15 months) and different window lengths (48 and 72) were also considered and the results were qualitatively similar (results are available from the authors upon request). Thus, we maintain that the results are not sensitive to the choice of the forecast horizon and/or the length of the rolling-windows.
} 
The time-varying connectedness measures are illustrated in Figure 3. As expected, total connectedness between stock market returns and oil price shocks behave rather heterogeneously over time and across countries. The range for the total connectedness plots span from values as low as $45 \%$ to values as high as $80 \%$ in almost all countries, implying that the interrelationship between oil price shocks and stock market returns do not remain constant; although a relative flat trend is observed at around $60 \%$ level. This is suggestive of the fact that throughout the sample period, regardless the economic or geopolitical conditions, the connectedness between oil price shocks and stock market returns are important.

Furthermore, a peak in the connectedness is observed during periods of economic turbulence and geopolitical unrest, such as, the Great Recession, the 2nd war in Iraq and the Start of the Arab Spring. Nevertheless, the peaks which are observed during the Great Recession period are unprecedent only for the net oil-exporting countries. This result confirms the findings by Awartani and Maghyereh (2013) who reported that the interrelationship between oil and GCC stock markets (net oil-exporters) peaked during the period of the Great Recession. Another interesting observation that can be made from Figure 3 is that a peak is observed in the connectedness measure for Russia and China in 2012 (i.e. during the escalation of the Syrian Civil War), whereas for all other countries, the measure either declines or fluctuates at relatively stable levels.

\section{[Insert Figure 3 around here]}

\subsubsection{Net directional connectedness between oil price shocks and stock market returns}

In an attempt to further disentangle the link between oil price shocks and stock market returns, we estimate model (1) using 60-month rolling windows and compute the timevarying net directional connectedness, as defined in equation (8). By concentrating on net directional connectedness we can deduce whether one of the variables is either a net transmitter or a net receiver of shocks within a particular country. ${ }^{3}$ Thus, we proceed by examining the net directional connectedness measure between stock market returns and oil price shocks. Initially, we concentrate on the nature (i.e. net transmitter or net recipient of shocks) of each one of the variables of interest in contrast with all other variables. The variable of interest is considered to be a net transmitter of shocks when the line lies within the positive upper part of each panel. Results are shown in Figure 4.

\section{[Insert Figure 4 around here]}

As can be seen in Figure 4, in the early period of our study and until the peak of the Great Recession, the net connectedness is taken over by the the aggregate demand shocks (ADS), whereas the reverse holds true for supply-side (SS) and oil-specific demand shocks (OSS). From that point onward, the opposite roles are observed where supply-side and oil-specific

\footnotetext{
${ }^{3}$ Net directional connectedness measures are estimated based on the gross directional connectedness measures. Thus, for sake of brevity and without loss of generality we only report here the net directional connectedness analysis. Nevertheless, the gross directional connectedness analysis, can be found in Appendix A.1.
} 
demand shocks assume a net transmitting role of connectedness for the largest part of this period (with the exception of Russia), whereas aggregate demand shocks (ADS) become net receivers of shocks. In addition, net directional connectedness measures for the supplyside and oil-specific demand shocks are relatively low compared with these of the aggregate demand shocks. The latter shocks reach a peak in the net transmission of shocks during the Great Recession. Overall, these results suggest that aggregate demand shocks (ADS) are more important compared to supply-side (SS) and (OSS) oil-specific demand shocks, in terms of their magnitude. This is in line with Basher et al. (2012); Filis et al. (2011); Kilian and Park (2009), among others, who also find evidence in favour of the importance of aggregate demand shocks.

Turning to innovations in stock market returns (SMR), these appear to be relatively stable in terms of magnitude throughout the period of study. However, in most countries they seem to frequently switch between a net transmitting and a net receiving role.

The net directional connectedness, defined in equation (8), has highlighted the importance of the aggregate demand shocks in this particular framework of study. However, we have not disentangled whether the net transmitting/receiving connectedness roles of these shocks is related to stock market returns or to any of the remaining two oil price shocks. Thus, we need to extend our dynamic analysis in order to uncover the net directional connectedness between each of the oil price shocks and stock market returns, concentrating on net pairwise connectedness, defined in equation (9), (see Figure 5). We should note that stock market returns are considered to be net transmitters (receivers) of shocks when the net connectedness measures receive negative (positive) values.

\section{[Insert Figure 5 around here]}

According to Figure 5, which reports the net pairwise connectedness measures, stock market returns (SMR) appear to be net transmitters of shocks to supply-side shocks (SS) throughout the pre-Great Recession period. The reverse picture is observed from 2009 onwards, when in most countries it is the supply-side shocks that assume the net transmitting role.

Pertaining to the relation between stock market returns (SMR) and aggregate demand shocks (ADS), apparently, in the pre-Great Recession period, the latter, clearly transmit shocks to the former. With the exception of Russia, this pattern reaches a climax during the peak years of the Great Recession, while in the post-Great Recession period and up until 2012 stock market returns act as net recipients of shocks from aggregate demand shocks (although this does not hold for China, whose stock market returns (SMR) transmit shocks immediately after the Great Recession). Post-2012 stock market returns (SMR) clearly assume a net transmitting role with respect to aggregate demand shocks, for all countries.

Considering the net pairwise connectedness between stock market returns (SMR) and oil-specific demand shocks (OSS), this appears to be rather low (with Russia being a notable exception) in the pre-Great Recession period, with the stock market being the net transmitter of shocks. Nevertheless, for most of the period after the 2009, stock market returns become net receivers of shocks from the oil-specific demand shocks. This holds for all countries apart from Russia. 
On a final note, there is no clear-cut evidence of any substantial differences between net oil-exporting and net oil-importing countries. Nevertheless, Russia seems to exhibit a different behaviour, compared to its group.

\subsection{Oil price shocks and stock market volatility}

Apart from investigating the various linkages between oil price shocks and stock market returns, our study further purports to explore the relation between oil price shocks and stock market uncertainty. We use realized volatility as our measure of current-looking volatility. ${ }^{4}$ For the purpose of brevity - given that the core of the analysis remains the same as in the previous section - we proceed with a succinct exposition of the findings referring to stock market volatility, merely emphasizing the main commonalities and differences with findings for stock market returns.

As far as total connectedness is concerned, results are shown in Table 3. The relevant average measure of connectedness assumes values within the range $15.8 \%$ (China) and $21.3 \%$ (Italy), which is suggestive as in the case of stock market returns of a moderate interdependence among the three disaggregated oil price shocks and realized volatility (SMRV). Following previous findings for stock market returns, we notice that aggregate demand shocks (ADS), contrary to supply-side (SS) and oil-specific demand shocks (OSS), have a net transmitting role. We further note that in connection with stock market volatility, Canada, China and the US appear to be at the receiving end of shocks during the period of the study.

\section{[Insert Table 3 around here]}

Turning to the evolution of connectedness over time, Figure 6 illustrates time-varying connectedness measures for realized volatility (SMRV) for all countries. As in the previous section for stock market returns, we notice that total connectedness behaves heterogeneously over time and across countries; while at the same time, it also appears to span within a similar range with values as low as $45 \%$ and as high as $85 \%$. A flat trend might again be identified at around the $60 \%$ level. In line with previous analysis, events such as the Great Recession, the start of the Arab Spring or the escalation of the Syrian civil war appear to drive connectedness shocks in most countries of our sample.

\section{[Insert Figure 6 around here]}

We then concentrate on net directional connectedness between oil price shocks and realised volatility (SMRV). Results are presented in Figure 7. On general principles, results closely resemble those reported in the previous section with both the peak of the Great Recession and the post-2012 period acting again as turning points signifying a switch in the

\footnotetext{
${ }^{4}$ We have also explored the robustness of our results based on another current-looking measure of volatility, namely, conditional volatility and the results remain qualitatively very similar with these of the realized volatility. Thus, for the sake of brevity, these results are not presented, but are available upon request.
} 
role assumed by each one of the variables of interest. It is worth noting that, although stock market volatility (SMRV) assumes a dual role for the most part of the period of study, in the years immediately before the beginning of the crisis it clearly assumes a net transmitting role of connectedness (with the exception of Japan and Russia).

\section{[Insert Figure 7 around here]}

Finally, we turn our attention to net pairwise connectedness. As evident in Figure 8, results do not qualitatively differ from those reported in the previous section. Both supplyside (SS) shocks and oil-specific shocks (OSS) begin to transmit shocks to stock market volatility (SMRV) after the peak years of the Great Recession. Aggregate demand shocks (ADS) on the other hand, appear to transmit shocks throughout the period of study and until 2012. In the post-2012 period, aggregate demand shocks (ADS) appear to receive shocks from stock market volatility (SMRV). With only a few exceptions (i.e. Germany and the US) connectedness between aggregate demand shocks (ADS) and stock market volatility (SMRV) appears to act in a similar manner irrespective of the particular group of country (i.e. net oil-importing or net oil-exporting).

\section{[Insert Figure 8 around here]}

\subsection{Robustness}

Given that the realised volatility of stock market returns is regarded as a current-looking measure of volatility, we reiterate the analysis between oil price shocks and forward-looking volatility, with the later now being approximated by the implied volatility of stock market options. According to Koopman et al. (2005), implied volatility is more informational efficient and thus it could provide additional information on the interdependencies between oil price shocks and stock market volatility. Implied volatility represents the market's expectation of stock market volatility over the next 30-day period, and as such, can provide additional insights for market participants' expectations on the link between oil price shocks and stock market volatility.

As the availability of implied volatility indices is rather limited, and our econometric approach very data intensive, we restrict our analysis only to the stock market indices for which implied volatilities exist from the 1990s. In particular, the countries (implied volatility series) that fulfill these criteria are France (VCAC), Germany (VDAX), Japan (VXJ), the UK (VFTSE) and the US (VIX).

As shown in Figure 2, the implied volatility indices are highly correlated with the realised and conditional measures of volatility. It is also evident that the implied volatility measure is relatively smoother than the realised volatility one.

The results based on the implied volatility measure are presented in Table 4 and Figures 9-11. Overall, there are no notable differences among the two historical and the forwardlooking measures of volatility, suggesting that implied volatility does not provide any superior information compared to the realized and/or conditional volatility.

[Insert Table 4 around here] 


\section{[Insert Figure 9 around here]}

[Insert Figure 10 around here]

[Insert Figure 11 around here]

As a final robustness check, we repeated the whole analysis, but with additional exogenous variables included in the VAR. In particular with experimented with the MSCI world index (that represents large and mid-cap equity performance across 23 developed markets countries, covering approximately $85 \%$ of the free float-adjusted market capitalization in each) in an attempt to control for global factors that might not have been captured in our main specification. Even after controlling for such global factors the results, which are available upon request, remain very robust.

\section{Discussion}

In order to gain a clearer understanding of the aforementioned relations, we now proceed with the interpretation of the formerly reported results. For the sake of brevity, our discussion builds on the empirical findings relating to net pairwise connectedness, ensuring though, that no important information is left out. In particular, we seek to identify which type of oil price shocks appears to be more important for the stock market, especially at times of recession or geopolitical turbulence. Nevertheless, country-specific analysis is also being reported, so as to trace the distinct dynamics of connectedness measures emanating from oil price shocks to the stock market of each country in our sample. As formerly mentioned, the cornerstone of our analysis is the Great Recession of 2007-2009; whereas, recent economic and geopolitical developments (i.e. the post-2010 period) are also of major concern. On a final note, our discussion revolves around the net pairwise connectedness measures illustrated in Figures 5 and 8.

Prominent among our results is the fact that in the period before and during the Great Recession, aggregate demand shocks act mainly as net transmitters of shocks to stock market returns and volatility. On the other hand, oil-specific demand shocks appear to act as net transmitters of shocks in the post-Great recession period. It is worth mentioning again, though, that the shocks transmitted from oil-specific demand shocks exhibit an increasing importance.

In close relation to this, authors such as Basher et al. (2012), Filis et al. (2011) and Kilian and Park (2009), among others, have already reported the increasing effects of the demand-side oil price shocks (but more importantly of the aggregate demand shocks) on stock market performance. In addition, our findings offer support to Degiannakis et al. (2014) who report that aggregate demand shocks affect stock market volatility.

The general consensus regarding this relationship is that positive aggregate demand shocks are regarded as positive news about economic activity and as such, trigger positive developments in the stock market. These positive developments are not only reflected by higher stock market returns (see, inter alia, Wang et al., 2013; Kilian and Park, 2009), but also by lower stock market volatility (Degiannakis et al., 2014). In this context, the fact 
that during the Great Recession aggregate demand shocks are primarily transmitting shocks to stock market returns and volatility, reveals that the negative aggregate demand shocks observed during this period, trigger negative responses from the stock markets and increase uncertainty. Furthermore, Bloom (2009) from a different standpoint, provides additional evidence to support the argument that negative news about global economic activity are likely to increase volatility in the stock market.

Moreover, the fact that oil-specific demand shocks are transmitting shocks to the stock markets in the post-Great Recession period, relates to the recent events in Syria and Libya, which raised concerns about the geopolitical stability of Middle East. Typically, such events raise concerns about the future availability of oil triggering significant oil-specific demand shocks, which drive stock market returns (volatility) in lower (higher) levels.

Another interesting finding is that during the last few months of the Great Recession and thereafter, stock market returns and volatilities are net recipients of shocks from supply-side shocks, although these effects are not very pronounced. These findings are not in line with previous studies who have demonstrated the insignificant effects of supply-side shocks in stock markets (see, inter alia Degiannakis et al., 2014; Basher et al., 2012; Filis et al., 2011). The consensus is that supply-side shocks do not cause any effects in the stock markets given that OPEC's decision regarding changes in oil supply are anticipated by the markets. Nevertheless, a plausible explanation of our result regarding the effects of supply-side shocks on stock market returns and volatility could lie on the fact that recent disruptions of oil supply are not related to OPEC decisions, but are rather related to unplanned oil supply disruptions caused by the Arab uprising, the oil theft in Nigeria and the closure of Libya's ports. Such developments are expected to trigger negative responses from the financial markets (i.e. lower returns and increased volatility).

Next, we concentrate on the country-specific results. A general comment regarding the relations of interest is that we are able to point out specific differences not only between groups, but also, within groups of countries. In particular, we notice that, with the exception of China, Japan and the US, all remaining net oil-importing countries in our sample (i.e. the European countries) exhibit certain differences compared to their net oil-exporting counterparts. As noted earlier, these differences are mainly related to the time-varying features of the link between oil price shocks and the stock market.

Starting with the net oil-exporting countries, the empirical findings for Canada suggest that, during turbulent times, aggregate demand shocks play a key role in the transmission process of shocks to the stock market. Specifically, during the years of the Great Recession - especially at the heart of the crisis - aggregate demand shocks appear to be significantly transmitted to both stock market returns and stock market volatility. This is somewhat expected given the aforementioned analysis in connection with the importance of aggregate demand shocks for the stock market. By contrast, aggregate demand shocks appear to be of a rather lesser importance during tranquil times. In fact, during the more recent years, it is the oil-specific demand and supply-side shocks which appear to be of greater importance. As previously noted, the importance of aggregate demand shocks for net oil-exporting countries has also been reported by Wang et al. (2013); however, this study provides additional evidence which accounts for the time-varying role of both oil-specific 
demand and supply-side shocks. Apergis and Miller (2009) also provide empirical evidence suggesting that oil-specific demand shocks mildly affect stock market returns in Canada without specifying though whether this influence relates to turbulent or tranquil periods. On a final note, it is important to emphasize that, during the years of the crisis, supply-side shocks were also on the transmitting end of shocks to the Canadian stock market, although to a lesser extent compared to shocks originating from aggregate demand shocks. This could potentially be explained on the basis of the importance of current availability of oil during periods of recession for net oil-exporting countries (see, among others, Antonakakis et al., 2014; Afonso and Furceri, 2010; Sturm et al., 2009), as well as, on the events that have taken place since the Great Recession in the Middle East.

As far as Norway is concerned, results are qualitatively very similar to those reported for Canada. However, both oil-specific demand and supply-side shocks seem to play a rather greater role in the Norwegian stock market in recent years. Jung and Park (2011) and Wang et al. (2013) also provide evidence of the persistent relation between the two demand-side shocks and the Norwegian stock market; nevertheless, this study suggests that supply-side shocks are also important at different time periods. Furthermore, bearing in mind the considerable effects of the volatility of the Norwegian stock market, we provide evidence that even relatively small stock markets may constitute a great source of influence - provided of course that the country under investigation is major player in the market for oil.

Turning to Russia, aggregate demand shocks appear to be important for stock market returns and volatility in the early stages of the Great Recession and until the peak years of the crisis. In addition, supply-side shocks are also important for both stock market returns and volatility, especially from the peak years of the crisis onwards. By contrast, oil-specific demand shocks do not appear to be important. This is in line with Antonakakis et al. (2014) who further subscribe to the belief that for net oil-exporting countries, both aggregate demand and supply-side shocks appear to be important during periods of economic downturn, while oil-specific demand shocks are likely to be more important during relatively even-tempered economic periods. This is true for Russia, although we cannot report any considerable shocks deriving from oil-specific demand shocks on the Russian stock market until the very recent years of our sample period. A potential explanation of the transition of shocks from aggregate demand shocks to supply-side shocks on the Russian stock market during the years of the Great Recession may lie in the work of Bhar and Nikolova (2010). These authors, put forward the argument (by referring to specific oil-related global disturbances such as the terrorist attack of September 11th 2001 and the 2003 war in Iraq) that, although on the eve of any oil price shock, concerns within the Russian economy are mainly demand driven. Eventually, at a later stage, Russia always acts as a resilient supplier of oil on every disturbing occasion; thereby raising concerns for future oil availability. In fact, Bhar and Nikolova (2010) provide historical evidence to support the argument that during such events, oil production within Russia has typically increased compared to production within other oil-producing countries. With regard to the prominence gained in recent years by shocks deriving from oil-specific demand shocks on the Russian stock market, authors such as Aleklett et al. (2010) explain that there have been considerations recently, regarding 
future oil production and thus oil availability within Russia, implying that a more targeted national policy regarding the security of future oil resources is rather essential. Reiterating a point made earlier, concerns regarding the future availability of oil in Russia (i.e. the resilient supplier) are likely to rise, especially in view of escalating upheaval in the Middle East.

Next, we concentrate on the net oil-importers, starting with the the Chinese stock market. We notice that during the years of the Great Recession, aggregate demand shocks are very important in the transmission process of shocks to both Chinese stock market returns and volatility; while clearly, supply-side shocks also assume a net transmitting role. Conversely, oil-specific demand shocks do not appear to be important throughout the years of the crisis. In turn, in the post-2012 period, oil-specific demand shocks appear to be important for Chinese stock market returns but not for stock market volatility. Considering that China is the world's second largest oil-importer (IEA, 2013), demand for oil can be a crucial factor affecting both stock market returns and volatility. Thus, the fact that Chinese stock market volatility is not receiving any shocks from oil-specific demand shocks in the post-2012 period is rather unexpected. It is worth mentioning though, that in recent years, authors such as Yuan et al. (2008), Zhang et al. (2009), as well as, Ma et al. (2012, 2011) raise concerns about the future availability of oil in China and stress the necessity for the formulation of appropriate governmental policies to secure oil reserves within the country, and shield the country against abrupt rises in the price of oil. Hence, potentially the Chinese stock market volatility does not currently react to oil-specific demand shocks anticipating that the new policy initiatives will be successfully implemented.

In Japan, aggregate demand shocks appear to be the dominant transmitters of shocks to both stock market characteristics especially during the first years of the crisis; however, these shocks seem to be more important in the transmisison process of connectedness to stock market volatility than to stock market returns. In addition, the same period is also characterised by the net transmitting role of oil-specific demand shocks. Empirical evidence related to the results presented in our study, can be found in the work of authors such as Abhyankar et al. (2013), who emphasize both the significant impact of aggregate demand shocks and the negative impact of oil-specific demand shocks on Japanese stock market returns. In addition, authors, such as Chang et al. (2013), emphasize that oil price shocks are, in general, key factors in explaining stock market volatility in Japan. Turning to the post-2012 period, connectedness mainly originates from supply-side and oil-specific demand shocks. These results are expected given the evidence provided by Abhyankar et al. (2013) and Chang et al. (2013) and the aforementioned geopolitical events that have taken place during this period.

Connectedness during the years of the Great Recession in the US is mainly taken over from aggregate demand shocks, especially during the first years of the crisis. We should note however, that this transmission process appears to be more important for stock market returns. Our results suggest, though, that there is definitely a key role for supply-side and oil-specific demand shocks during the latter part of our study. Once again, even in the case of the US we observe the impact of the recent events in the Middle East in the stock market returns and volatility. Our findings are somewhat in line with the empirical evidence 
by Kilian and Park (2009), who argue that supply-side shocks are less important to the US stock market, compared to the two demand-side shocks. Nevertheless, in this study we point out that the importance of each oil price shock to stock market returns and volatility cannot be examined in a static environment as it clearly depends on events that take place at different time periods.

Finally, aggregate demand shocks are the front runners of connectedness during the Great Recession in European countries. However, volatility in European stock markets appears to also be influenced by both supply-side and oil-specific demand shocks. It is worth noting that most existing studies on European stock markets concentrate on stock market returns (i.e. excluding stock market volatility) within a static framework in order to provide evidence that entails either a minimum or a negligible influence originating from supply-side shocks. From the few studies focusing on the stock market volatility in Europe, Degiannakis et al. (2014) provide specific evidence that it is aggregate demand shocks rather than the other two that mostly influence volatility in European stock markets. Apparently, though, at turbulent economic or geopolitical times, supply-side and oil-specific demand shocks are also important for the volatility of European stock markets given that these shocks act as net transmitters, too. Especially the net transmitting role of the oil-specific demand shocks to both stock market returns and volatility in European countries that is observed in the post-2012 period signifies the importance of the ongoing Middle East crisis to these stock markets.

In conclusion, our results suggest that aggregate demand shocks are the main transmitters of shocks to the stock markets during periods of economic turbulence, whereas supply-side and oil-specific demand shocks seem to increase the connectedness during periods of geopolitical unrest. Our findings also indicate the importance of adopting a dynamic approach so as to capture the relevance of each type of shock and to trace similarities and differences between the various types of countries over time.

\section{Conclusion}

Attaining deeper understanding regarding the relationship between oil price shocks and the stock market appears to be of major concern to recent relevant literature. Contemporary research in this field typically breaks down into three main strands; that is, (i) the investigation of the effects of oil price shocks on the stock market considering the origin of the shock, (ii) the investigation of whether there exists a time-varying relationship between oil prices and the stock market, as well as, (iii) the investigation of potential spillover effects between the said markets.

In this respect, the main contribution of this study is that it combines all three aforementioned strands of related literature in order to investigate the connectedness between oil price shocks (i.e. shocks disaggregated by virtue of their origin) and 11 major stock markets of the world (including both stock markets of net oil-importing and of net oil-exporting countries), within a time-varying framework. The period of the study spans from September 1995 to July 2013. The employed methodology is the one proposed by Diebold and Yilmaz (2014), which in this study is being further extended by the application of a structural vec- 
tor autoregressive framework that allows for the identification of the three different types of oil price shocks. It follows that this study adds to existing literature not only in terms of introducing new evidence regarding the relationship under investigation, but also, in terms of further exploiting existing econometric methods.

Furthermore, this study concentrates on two stock market characteristics; namely, stock market returns and stock market volatility. One of the major concerns of the authors is to also investigate whether consistent results regarding the behaviour of both stock market characteristics can indeed be obtained (whether, for example, a negative shock that triggers negative responses from stock market returns also creates higher stock market volatility). We employ both current-looking (conditional and realised) and forward-looking (implied) measures of stock market volatility in order to investigate whether the forward-looking measure can indeed provide better information, as has been suggested by the literature.

The implementation of the specific econometric method allows for the investigation of connectedness from three different angles. In particular, we are able to calculate total, gross directional, as well as, net directional connectedness measures between oil price shocks and the stock market. Total and gross directional connectedness measures, draw a broader picture of the relationship under investigation, providing information about the magnitude, the trend, as well as, the level of shocks either received or transmitted by each one of the variables of the study. Net directional connectedness measures, on the other hand, provide specific information regarding the role of each variable under investigation throughout the period of study (i.e. net transmitter or net recipient of shocks). What is more, net directional connectedness measures can be further specified in order to facilitate a net pairwise investigation approach (i.e. net effects between variables).

Empirical findings suggest that considering both a time-varying framework of study and the disaggregation of oil price shocks by virtue of their origin is of cardinal importance. To be more explicit, we provide evidence that connectedness indeed varies across time and that its direction and magnitude is closely related to global economic developments. Furthermore, we find that not all types of oil price shocks transmit shocks to the stock market at the same time, but rather, this also depends on the specific period under investigation. More specifically, considering net pairwise connectedness, our evidence indicates that aggregate demand shocks appear to be net transmitters of shocks to the stock market during turbulent economic periods (e.g. during the years of the Great Recession), while both supply-side and oil-specific demand shocks act as net transmitters of shocks during periods characterised by intense global geopolitical unrest.

Results are also indicative of the fact that connectedness may differ not only between the two groups of countries under investigation (i.e. net oil-importing and net oil-exporting countries) but also among the countries of each group. These differences can be partly attributed to the time-varying character of the relationship between oil price shocks and the stock market. What is more, we provide no evidence that the forward-looking measure of stock market volatility provides superior information compared to the current-looking measure.

Our findings are important to investors and portfolio managers who have positions to both the oil and the stock markets and thus need to adjust their holdings according to 
the level of connectedness of the two markets. In particular, investors should strongly consider the fact that different oil price shocks transmit different shocks over different time periods that result in different correlations within a portfolio comprising investments in both markets. For instance, shocks originating from aggregate demand shocks tend to strengthen the co-movement of the two markets, while shocks originating from both supply-side and oil-specific demand shocks entail negative correlation. These results are also important to investors who participate in the options market given that volatility is the key component of option pricing. Thus, they need to be aware of the time-varying nature of potential shocks that oil price shocks transmit to stock market volatility.

An exciting avenue for future research may include the examination of connectedness between oil price shocks and industrial sectors rather than aggregate stock indices. Aggregate stock market indices may mask the individual characteristics of the industrial sectors. Finally, the examination of interdependence between oil price shocks and other financial assets (e.g. exchange rates) and commodity price indices (e.g. gold or food), which form part of investment portfolios, is an interesting area for further research. In close relation to this, in order to make the analysis more relevant to actual trading strategies, potential future research should also involve stock index futures data as, according to authors such as Yarovaya et al. (2016), these instruments present investors with greater opportunities for diversification.

\section{Acknowledgements}

We like to thank the editor (Brian Lucey), two anonymous referees and the participants of the 13th INFINITI conference, the International Conference on Energy prices: macroeconomic and financial impacts, and the staff seminars held at the University of Portsmouth and Bournemouth University, for their invaluable comments and suggestions on a previous version of this paper. The usual disclaimer applies.

\section{References}

Abhyankar, A., Bing, X., Jiayue, W., 2013. Oil price shocks and the stock market: Evidence from Japan. The Energy Journal 34 (2), 199-222.

Afonso, A., Furceri, D., 2010. Government size, composition, volatility and economic growth. European Journal of Political Economy 26 (4), 517-532.

Aleklett, K., Höök, M., Jakobsson, K., Lardelli, M., Snowden, S., Söderbergh, B., 2010. The peak of the oil age-analyzing the world oil production reference scenario in world energy outlook 2008. Energy Policy 38 (3), 1398-1414.

Alquist, R., Kilian, L., 2010. What do we learn from the price of crude oil futures? Journal of Applied Econometrics 25 (4), 539-573.

Alter, A., Beyer, A., 2014. The dynamics of spillover effects during the European sovereign debt turmoil. Journal of Banking \& Finance 42, 134-153.

Alter, A., Schüler, Y. S., 2012. Credit spread interdependencies of European states and banks during the financial crisis. Journal of Banking $\&$ Finance 36 (12), 3444-3468.

Antonakakis, N., 2012. Exchange return co-movements and volatility spillovers before and after the introduction of euro. Journal of International Financial Markets, Institutions and Money 22 (5), 1091-1109. 
Antonakakis, N., Chatziantoniou, I., Filis, G., 2014. Dynamic spillovers of oil price shocks and economic policy uncertainty. Energy Economics.

Antonakakis, N., Filis, G., 2013. Oil prices and stock market correlation: A time-varying approach. International Journal of Energy and Statistics 1 (01), 17-29.

Apergis, N., Lau, M. C. K., Yarovaya, L., 2016. Media sentiment and cds spread spillovers: Evidence from the giips countries. International Review of Financial Analysis 47, 50-59.

Apergis, N., Miller, S. M., 2009. Do structural oil-market shocks affect stock prices? Energy Economics 31 (4), 569-575.

Arouri, M. E. H., Jouini, J., Nguyen, D. K., 2011a. Volatility spillovers between oil prices and stock sector returns: implications for portfolio management. Journal of International Money and Finance 30 (7), 1387-1405.

Arouri, M. E. H., Jouini, J., Nguyen, D. K., 2012. On the impacts of oil price fluctuations on European equity markets: Volatility spillover and hedging effectiveness. Energy Economics 34 (2), 611-617.

Arouri, M. E. H., Lahiani, A., Nguyen, D. K., 2011b. Return and volatility transmission between world oil prices and stock markets of the GCC countries. Economic Modelling 28 (4), 1815-1825.

Asteriou, D., Bashmakova, Y., 2013. Assessing the impact of oil returns on emerging stock markets: A panel data approach for ten Central and Eastern European countries. Energy Economics 38, 204-211.

Awartani, B., Maghyereh, A. I., 2013. Dynamic spillovers between oil and stock markets in the Gulf Cooperation Council countries. Energy Economics 36, 28-42.

Baker, S. R., Bloom, N., Davis, S. J., 2016. Measuring economic policy uncertainty. The Quarterly Journal of Economics.

Baruník, J., Kočenda, E., Vácha, L., 2016. Asymmetric connectedness on the U.S. stock market: Bad and good volatility spillovers. Journal of Financial Markets 27 (C), 55-78.

Barunik, J., Krehlik, T., 2015. Measuring the frequency dynamics of financial and macroeconomic connectedness. Available at SSRN 2627599.

Basher, S. A., Haug, A. A., Sadorsky, P., 2012. Oil prices, exchange rates and emerging stock markets. Energy Economics 34 (1), 227-240.

Baumeister, C., Peersman, G., 2013. Time-varying effects of oil supply shocks on the US economy. American Economic Journal: Macroeconomics 5 (4), 1-28.

Bhar, R., Nikolova, B., 2010. Global oil prices, oil industry and equity returns: Russian experience. Scottish Journal of Political Economy 57 (2), 169-186.

Bjørnland, H. C., 2009. Oil price shocks and stock market booms in an oil exporting country. Scottish Journal of Political Economy 56 (2), 232-254.

Bloom, N., 2009. The impact of uncertainty shocks. Econometrica 77 (3), 623-685.

Broadstock, D., Filis, G., 2014. Oil price shocks and stock market returns: New evidence from the United States and China. Journal of International Financial Markets, Institutions and Money 33, 417-433.

Broadstock, D. C., Cao, H., Zhang, D., 2012. Oil shocks and their impact on energy related stocks in China. Energy Economics 34 (6), 1888-1895.

Brown, S. P., Yucel, M. K., 1999. Oil prices and us aggregate economic activity: a question of neutrality. Economic \& Financial Review, 16.

Bubák, V., Kočenda, E., Žikeš, F., 2011. Volatility transmission in emerging European foreign exchange markets. Journal of Banking 65 Finance 35 (11), 2829-2841.

Büyükşahin, B., Robe, M. A., 2014. Speculators, commodities and cross-market linkages. Journal of International Money and Finance 42, 38-70.

Chang, C.-L., McAleer, M., Tansuchat, R., 2013. Conditional correlations and volatility spillovers between crude oil and stock index returns. The North American Journal of Economics and Finance 25, $116-138$.

Chen, S.-S., 2010. Do higher oil prices push the stock market into bear territory? Energy Economics 32 (2), 490-495.

Choi, K., Hammoudeh, S., 2010. Volatility behavior of oil, industrial commodity and stock markets in a regime-switching environment. Energy Policy 38 (8), 4388-4399.

Ciner, C., 2013. Oil and stock returns: Frequency domain evidence. Journal of International Financial 
Markets, Institutions and Money 23, 1-11.

Claeys, P., Vašíček, B., 2014. Measuring bilateral spillover and testing contagion on sovereign bond markets in Europe. Journal of Banking \& Finance 46, 151-165.

Degiannakis, S., Filis, G., Kizys, R., 2014. The effects of oil price shocks on stock market volatility: Evidence from European data. The Energy Journal 35 (1), 35-56.

Diebold, F. X., Yilmaz, K., 2009. Measuring financial asset return and volatility spillovers, with application to global equity markets. Economic Journal 119 (534), 158-171.

Diebold, F. X., Yilmaz, K., 2012. Better to give than to receive: Predictive directional measurement of volatility spillovers. International Journal of Forecasting 28 (1), 57-66.

Diebold, F. X., Yilmaz, K., 2014. On the network topology of variance decompositions: Measuring the connectedness of financial firms. Journal of Econometrics 182 (1), 119-134.

Fattouh, B., Kilian, L., Mahadeva, L., 2013. The role of speculation in oil markets: What have we learned so far? The Energy Journal 34, 7-33.

Fattouh, B, K. L. M. L., 2010. The role of speculation in oil markets: What have we learned so far? Energy Journal 34, 7-33.

Filis, G., 2010. Macro economy, stock market and oil prices: Do meaningful relationships exist among their cyclical fluctuations? Energy Economics 32 (4), 877-886.

Filis, G., 2014. Time-varying co-movements between stock market returns and oil price shocks. International Journal of Energy and Statistics 2 (01), 27-42.

Filis, G., Chatziantoniou, I., 2014. Financial and monetary policy responses to oil price shocks: evidence from oil-importing and oil-exporting countries. Review of Quantitative Finance and Accounting 42 (4), $709-729$

Filis, G., Degiannakis, S., Floros, C., 2011. Dynamic correlation between stock market and oil prices: The case of oil-importing and oil-exporting countries. International Review of Financial Analysis 20 (3), 152164.

Hamilton, J. D., 1996. This is what happened to the oil price-macroeconomy relationship. Journal of Monetary Economics 38 (2), 215-220.

Hamilton, J. D., 2009a. Causes and consequences of the oil shock of 2007-08. Brookings Papers on Economic Activity 40 (1), 215-261.

Hamilton, J. D., 2009b. Understanding crude oil prices. The Energy Journal 30 (2), 179-206.

Hamilton, J. D., Wu, J. C., 2014. Risk premia in crude oil futures prices. Journal of International Money and Finance 42, 9-37.

IEA, 2013. International Energy Agency Key World Energy Statistics 2013. URL http://www.iea.org/publications/freepublications/publication/name, 31287 , en.html

Jiang, G. J., Konstantinidi, E., Skiadopoulos, G., 2012. Volatility spillovers and the effect of news announcements. Journal of Banking \& Finance 36 (8), 2260-2273.

Jones, C. M., Kaul, G., 1996. Oil and the stock markets. The Journal of Finance 51 (2), 463-491.

Jones, D. W., Leiby, P. N., Paik, I. K., 2004. Oil price shocks and the macroeconomy: what has been learned since 1996. The Energy Journal, 1-32.

Jung, H., Park, G., 2011. Stock markets reaction to oil price shocks: A comparison between an oil-importing economy and an oil-exporting economy. Journal of Economic Theory and Econometrics 22, 1-29.

Kang, W., Ratti, R. A., 2013. Structural oil price shocks and policy uncertainty. Economic Modelling 35, 314-319.

Kilian, L., 2009. Not all oil price shocks are alike: Disentangling demand and supply shocks in the crude oil market. The American Economic Review 99 (3), 1053-1069.

Kilian, L., Park, C., 2009. The impact of oil price shocks on the US stock market. International Economic Review 50 (4), 1267-1287.

Koop, G., Pesaran, M. H., Potter, S. M., 1996. Impulse response analysis in nonlinear multivariate models. Journal of Econometrics 74 (1), 119-147.

Koopman, S. J., Jungbacker, B., Hol, E., 2005. Forecasting daily variability of the S\&P 100 stock index using historical, realised and implied volatility measurements. Journal of Empirical Finance 12 (3), 445-475. 
Laopodis, N. T., 2011. Equity prices and macroeconomic fundamentals: International evidence. Journal of International Financial Markets, Institutions and Money 21 (2), 247-276.

Lee, Y.-H., Chiou, J.-S., 2011. Oil sensitivity and its asymmetric impact on the stock market. Energy 36 (1), $168-174$.

Lippi, F., Nobili, A., 2012. Oil and the macroeconomy: A quantitative structural analysis. Journal of the European Economic Association 10 (5), 1059-1083.

Ma, L., Fu, F., Li, Z., Liu, P., 2012. Oil development in China: Current status and future trends. Energy Policy 45 (0), 43-53.

Ma, L., Liu, P., Fu, F., Li, Z., Ni, W., 2011. Integrated energy strategy for the sustainable development of China. Energy 36 (2), 1143-1154.

Malik, F., Ewing, B. T., 2009. Volatility transmission between oil prices and equity sector returns. International Review of Financial Analysis 18 (3), 95-100.

Malik, F., Hammoudeh, S., 2007. Shock and volatility transmission in the oil, US and Gulf equity markets. International Review of Economics \& Finance 16 (3), 357-368.

McMillan, D. G., Speight, A. E., 2010. Return and volatility spillovers in three euro exchange rates. Journal of Economics and Business 62 (2), 79-93.

Mensi, W., Beljid, M., Boubaker, A., Managi, S., 2013. Correlations and volatility spillovers across commodity and stock markets: Linking energies, food, and gold. Economic Modelling 32, 15-22.

Miller, J. I., Ratti, R. A., 2009. Crude oil and stock markets: Stability, instability, and bubbles. Energy Economics 31 (4), 559-568.

Mohanty, S. K., Nandha, M., Turkistani, A. Q., Alaitani, M. Y., 2011. Oil price movements and stock market returns: Evidence from Gulf Cooperation Council (GCC) countries. Global Finance Journal 22 (1), 42-55.

Morana, C., 2013. Oil price dynamics, macro-finance interactions and the role of financial speculation. Journal of Banking \& Finance 37 (1), 206-226.

Narayan, P. K., Sharma, S. S., 2011. New evidence on oil price and firm returns. Journal of Banking 8 Finance 35 (12), 3253-3262.

Pesaran, H. H., Shin, Y., 1998. Generalized impulse response analysis in linear multivariate models. Economics Letters 58 (1), 17-29.

Sadorsky, P., 2012. Correlations and volatility spillovers between oil prices and the stock prices of clean energy and technology companies. Energy Economics 34 (1), 248-255.

Sadorsky, P., 2014. Modeling volatility and correlations between emerging market stock prices and the prices of copper, oil and wheat. Energy Economics 43, 72-81.

Sims, C., 1980. Macroeconomics and reality. Econometrica 48, 1-48.

Sturm, M., Gurtner, F. J., Gonzalez, J., 2009. Fiscal Policy Challenges in Oil-Exporting Countries - A Review of Key Issues. ECB Occasional Paper Series 104, European Central Bank (ECB).

Wang, Y., Wu, C., Yang, L., 2013. Oil price shocks and stock market activities: Evidence from oil-importing and oil-exporting countries. Journal of Comparative Economics 41 (4), 1220-1239.

Yarovaya, L., Brzeszczyński, J., Lau, C. K. M., 2016. Intra-and inter-regional return and volatility spillovers across emerging and developed markets: Evidence from stock indices and stock index futures. International Review of Financial Analysis 43, 96-114.

Yuan, J.-H., Kang, J.-G., Zhao, C.-H., Hu, Z.-G., 2008. Energy consumption and economic growth: Evidence from China at both aggregated and disaggregated levels. Energy Economics 30 (6), 3077-3094.

Zhang, X.-B., Fan, Y., Wei, Y.-M., 2009. A model based on stochastic dynamic programming for determining China's optimal strategic petroleum reserve policy. Energy Policy 37 (11), 4397-4406. 
Figure 1: Oil production growth, oil returns, general economic activity \& stock market returns Panel A: Oil Production, Oil Price \& General Economic Activity

Figure 2: Stock market returns' realised volatility, conditional volatility \& implied volatility

Panel A: Oil Exporting Countries
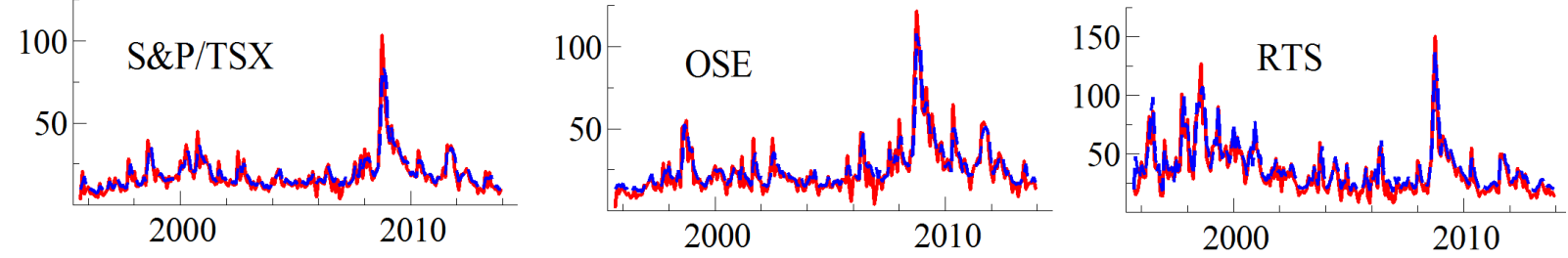

Panel B: Oil Importing Countries

Figure 3: Total connectedness measure between oil price shocks and stock market returns

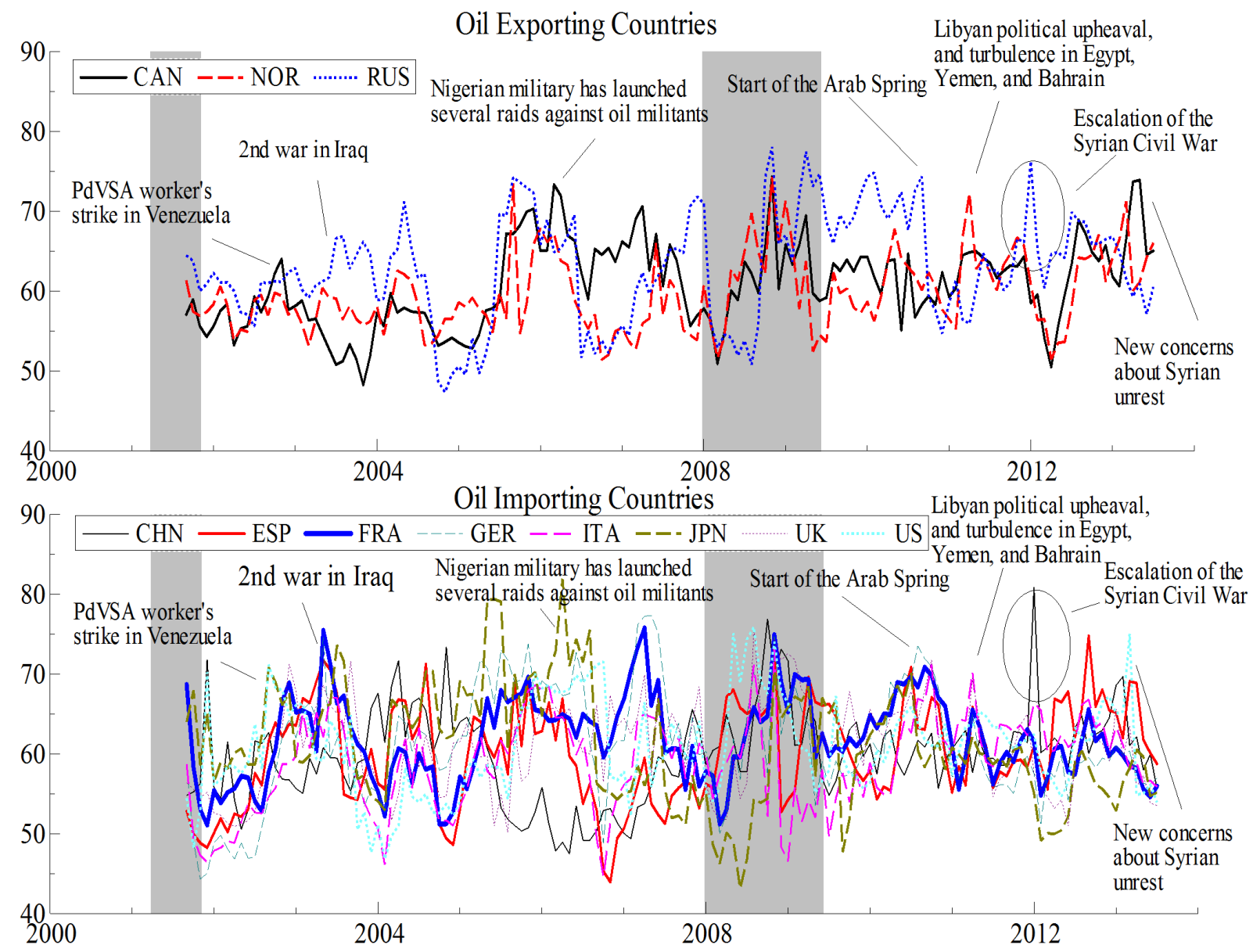

Note: Shading denotes US recessions as defined by the NBER. 
Figure 4: Net directional connectedness of oil price shocks and stock market returns

Oil Exporting Countries
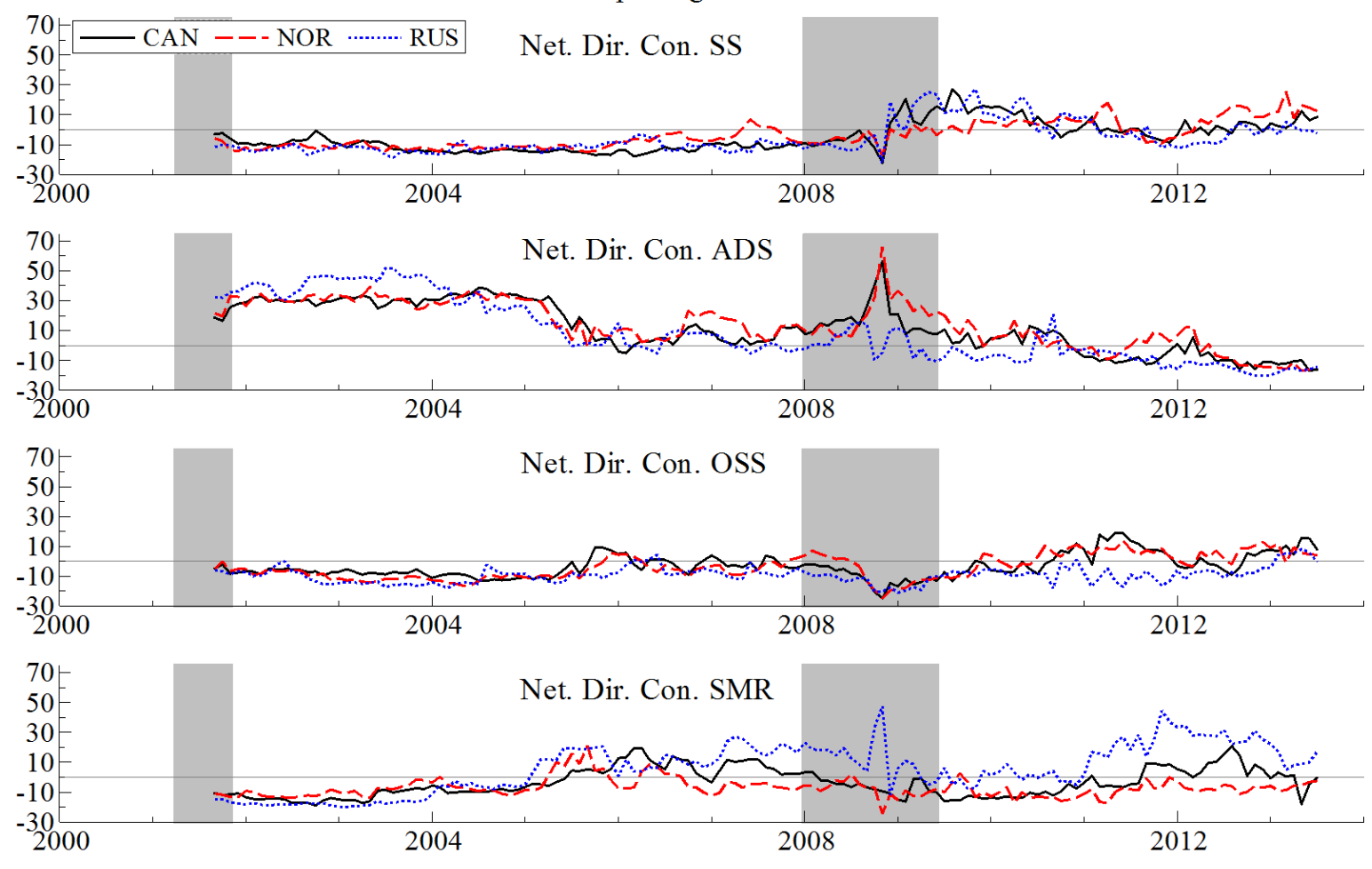

Oil Importing Countries

Figure 5: Net pairwise connectedness between oil price shocks and stock market returns Oil Exporting countries



Oil Importing countries

Figure 6: Total connectedness measure between oil price shocks and stock market realised volatility

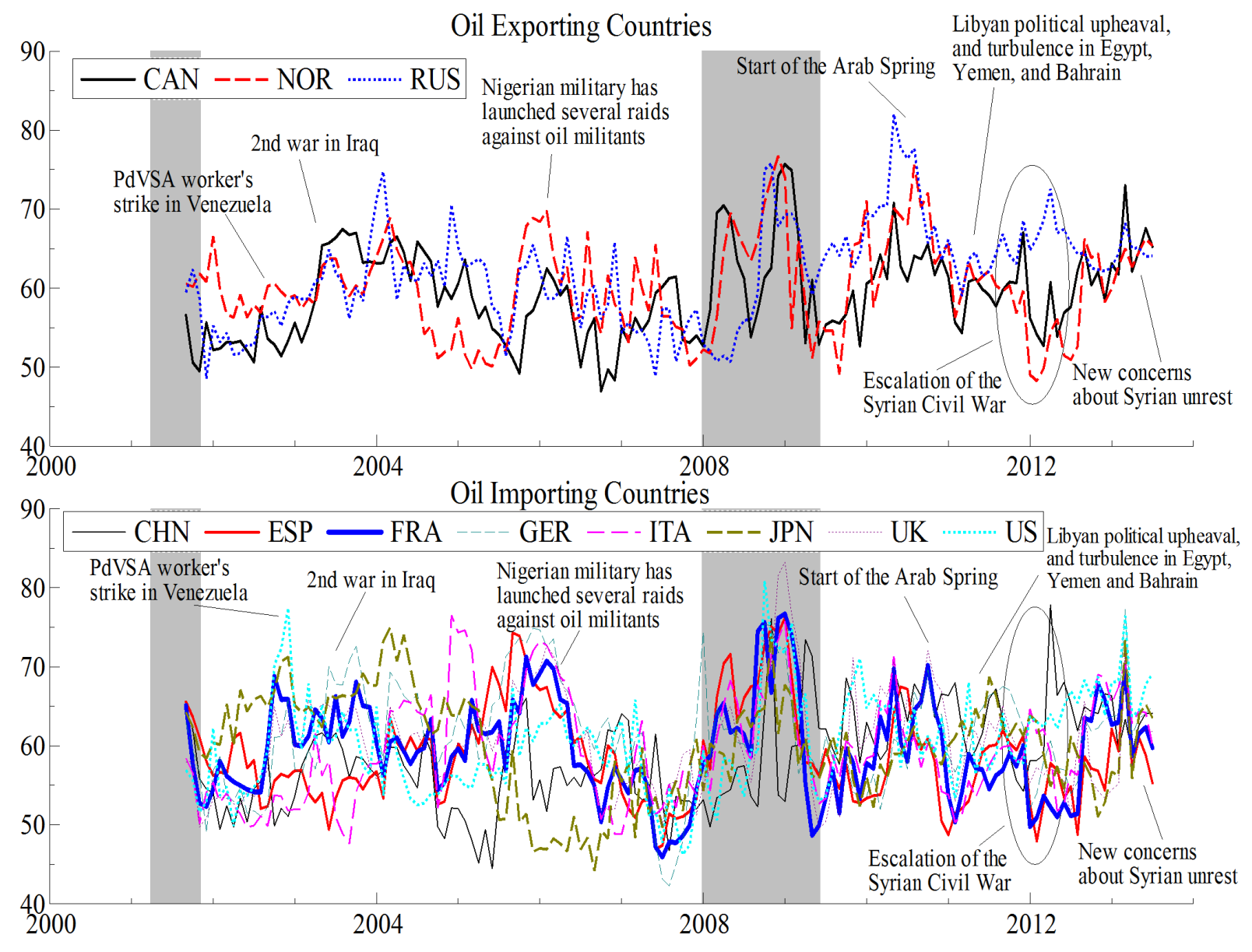

Note: Shading denotes US recessions as defined by the NBER. 
Figure 7: Net directional connectedness of oil price shocks and stock market realised volatility
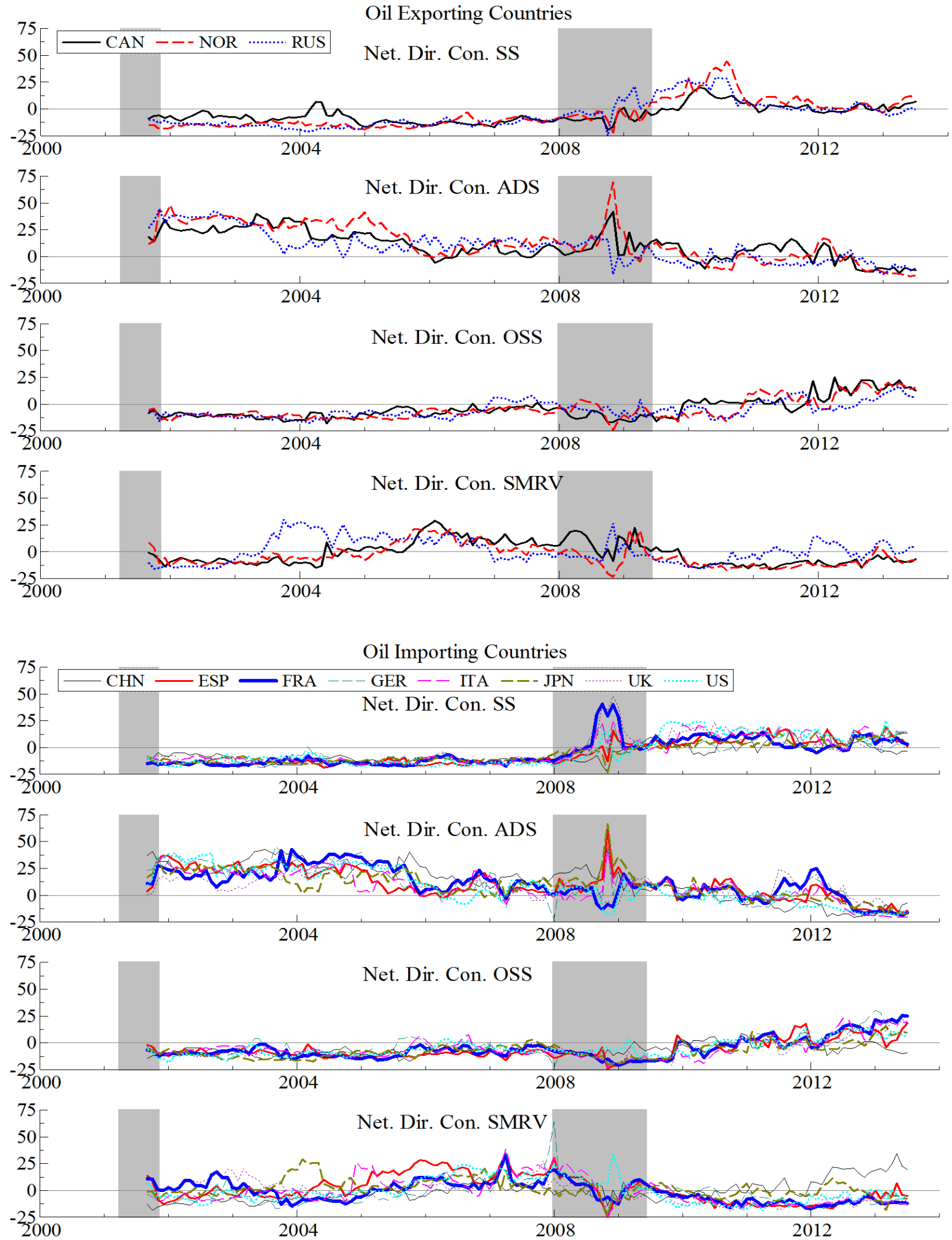
Figure 8: Net pairwise connectedness between oil price shocks and stock market realised volatility Oil Exporting Countries


Oil Importing Countries
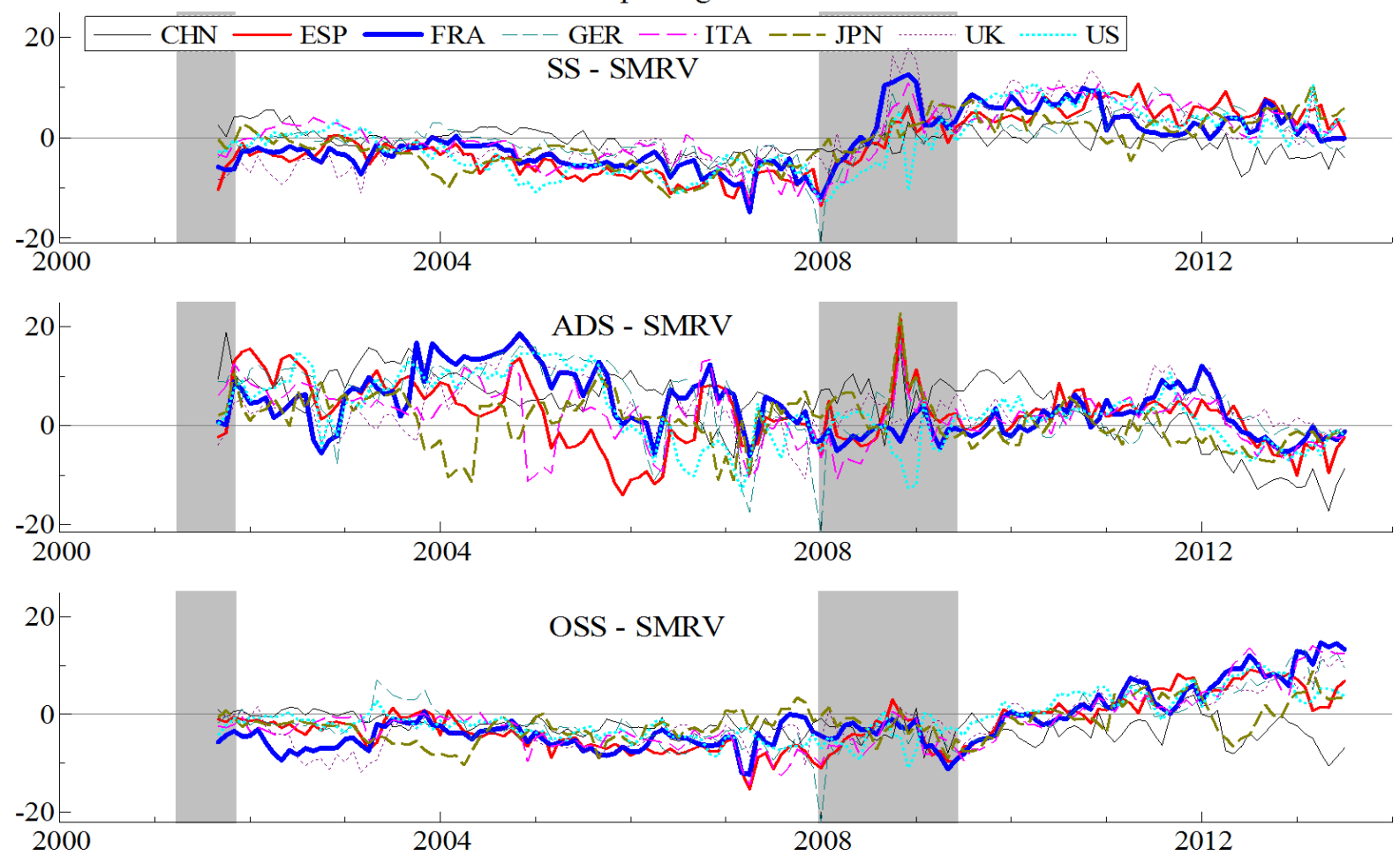
Figure 9: Total connectedness measure between oil price shocks and stock market implied volatility

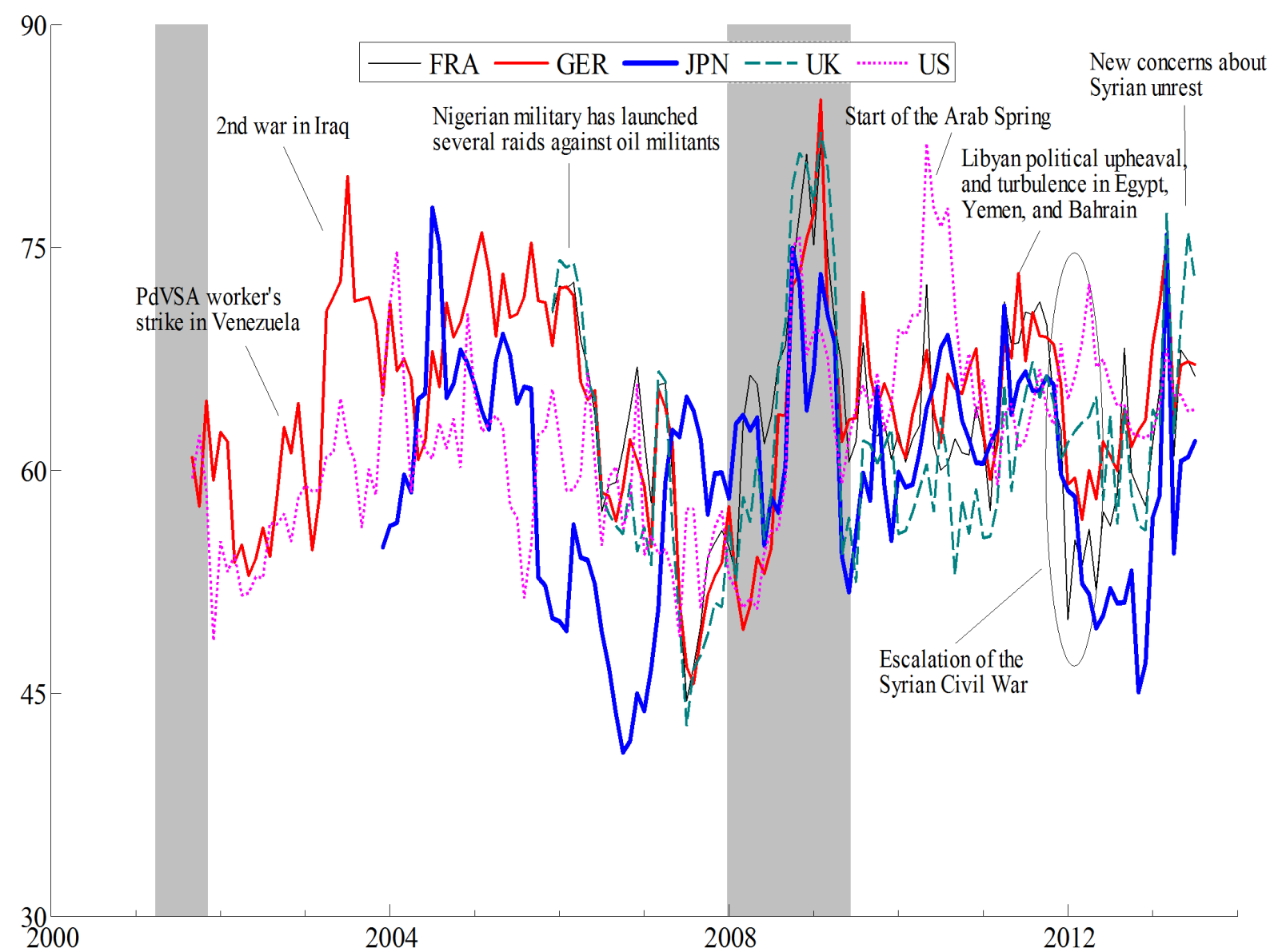

Note: Shading denotes US recessions as defined by the NBER. 
Figure 10: Net directional connectedness of oil price shocks and stock market implied volatility

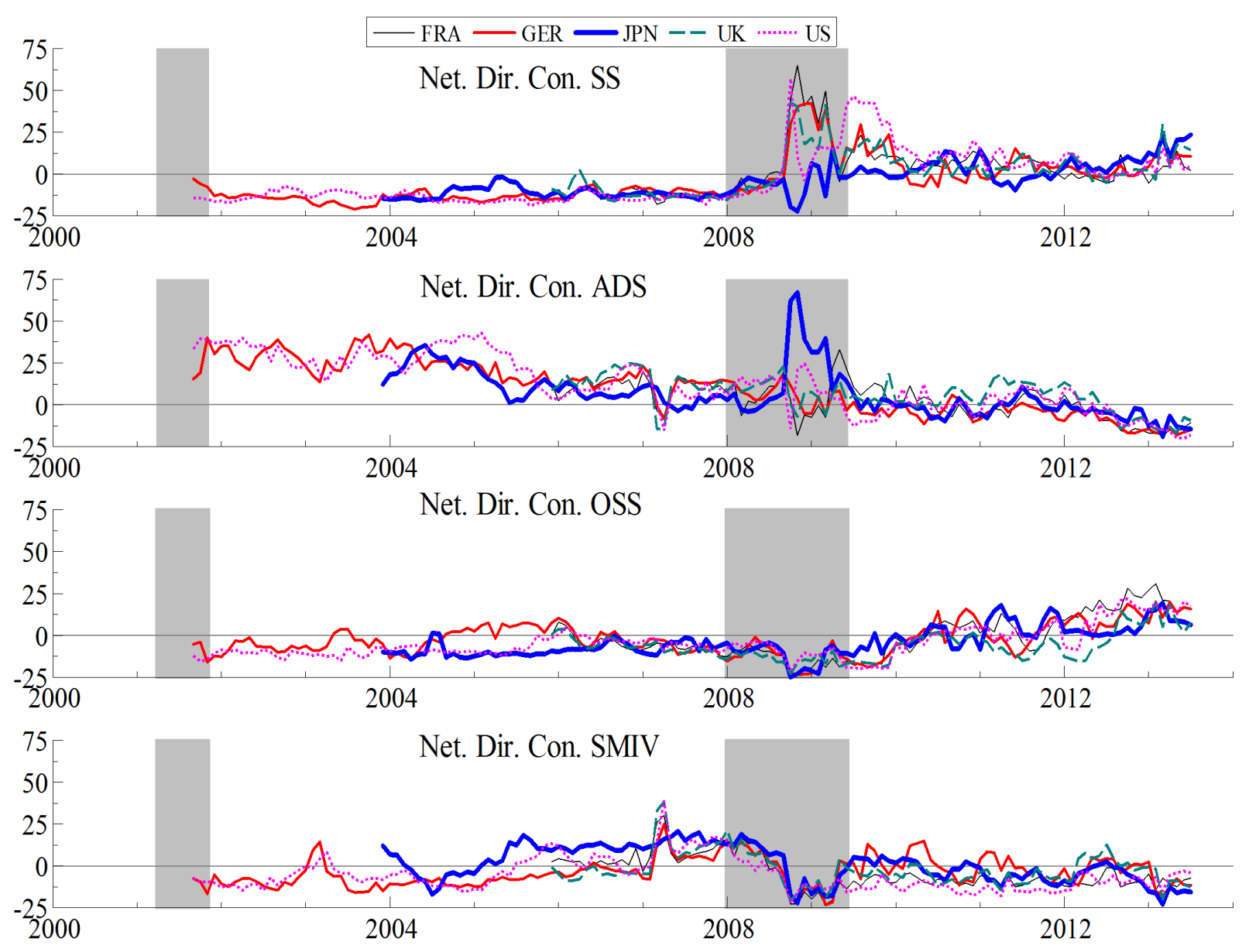


Figure 11: Net pairwise connectedness between oil price shocks and stock market implied volatility
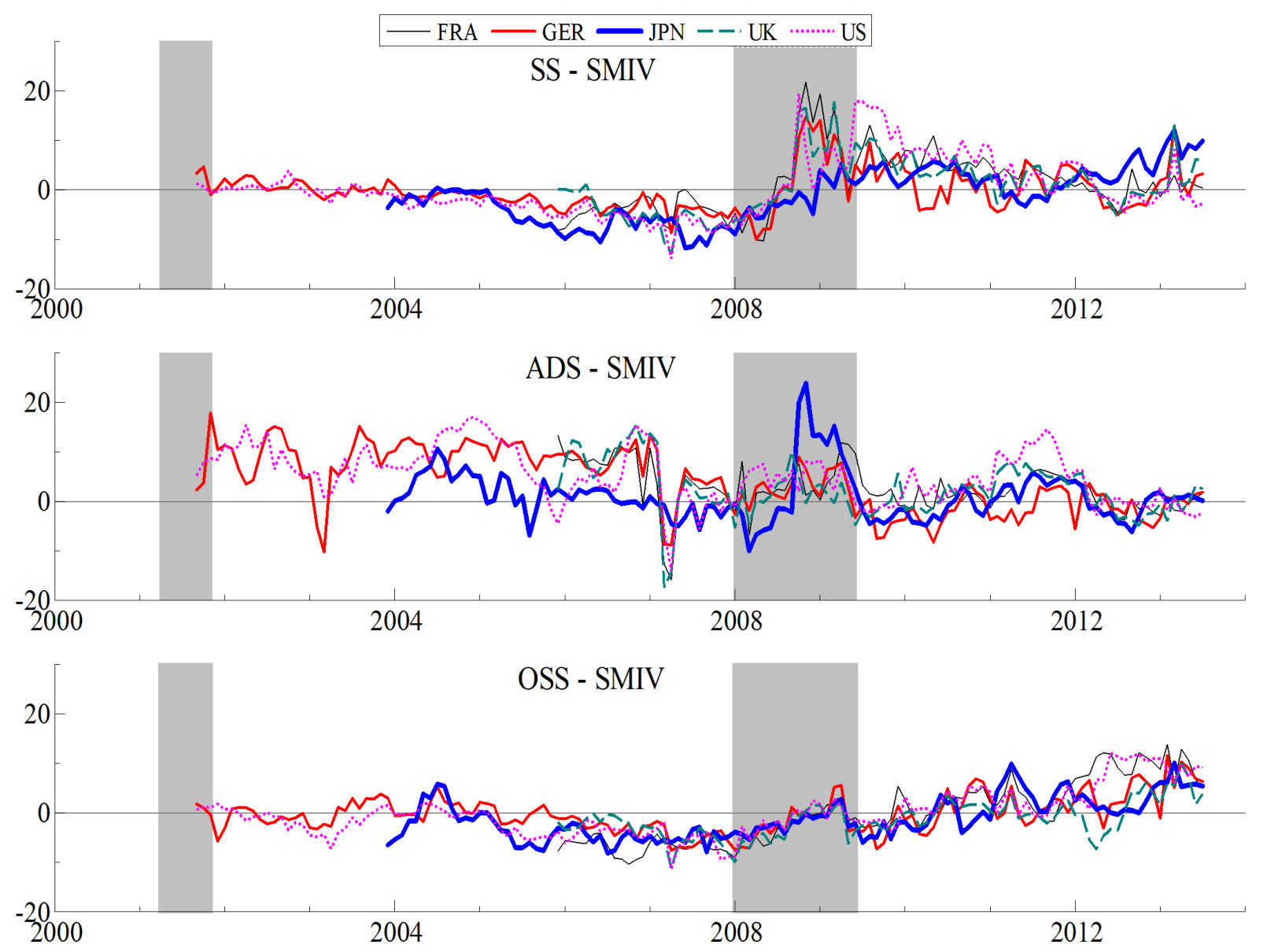
Table 1: Descriptive statistics, 1995:09 - 2013:07

\begin{tabular}{|c|c|c|c|c|c|c|}
\hline Series & Obs Mean & Min & Skewness & Excess Kurtosis & Jarque-Bera & $\mathrm{ADF}$ \\
\hline Global Economic Activity (GEA) & 2152.1896 & $27.674-50.300$ & 59.1000 .2286 & $-0.9843^{* *}$ & $10.502^{* *}$ & $-2.993^{*}$ \\
\hline$\Delta \ln (\mathrm{OIL}$ PRICE $)$ & 2140.0087 & $0.0898-0.3110$ & $0.2007-0.7755^{* *}$ & $1.0657^{* *}$ & $31.574^{* *}$ & $-11.93^{* *}$ \\
\hline \multirow[t]{2}{*}{$\Delta \ln (\mathrm{OIL}$ PROD $)$} & 2140.0012 & $0.0080-0.0249$ & $0.0259-0.0877$ & $1.0379^{* *}$ & $9.8796^{* *}$ & $-15.05^{* *}$ \\
\hline & \multicolumn{6}{|c|}{ Oil-Exporting Countries } \\
\hline \multicolumn{7}{|l|}{ Returns } \\
\hline$\Delta \ln (\mathrm{S} \& \mathrm{P} / \mathrm{TSX})$ & 2140.0060 & $0.0599-0.3695$ & $0.1612-1.4062^{* *}$ & $6.5226^{* *}$ & $449.88^{* * *}$ & $-12.10^{* *}$ \\
\hline$\Delta \ln (\mathrm{OSE})$ & $214 \quad 0.0079$ & $0.0742-0.4369$ & $0.1972-1.2884^{* *}$ & $5.3154^{* *}$ & $311.13^{* *}$ & $-11.72^{* *}$ \\
\hline$\Delta \ln (\mathrm{RTS})$ & $214 \quad 0.0122$ & $0.1431-0.6173$ & $0.5408-0.8889^{* *}$ & $3.4226^{* *}$ & $132.63^{* *}$ & $-12.02^{* *}$ \\
\hline \multicolumn{7}{|l|}{ Realised Volatility } \\
\hline $\mathrm{S} \& \mathrm{P} / \mathrm{TSXRV}$ & 21418.662 & 11.5233 .8878 & $103.423 .2010^{* *}$ & $16.880^{* *}$ & $2987.7^{* *}$ & $-5.625^{* *}$ \\
\hline OSERV & 21425.092 & 16.1342 .5305 & $121.672 .5882^{* *}$ & $9.4901^{* *}$ & $1071.2^{* *}$ & $-5.429 * *$ \\
\hline RTSRV & 21435.848 & 21.4908 .1671 & $150.171 .8686^{* *}$ & $5.0095^{* *}$ & $358.06^{* *}$ & $-6.213^{* *}$ \\
\hline \multicolumn{7}{|l|}{ Conditional Volatility } \\
\hline $\mathrm{S} \& \mathrm{P} / \mathrm{TSXCV}$ & 21419.382 & 10.3277 .62 & $83.3303 .2923^{* *}$ & $15.620^{* *}$ & $2574.2^{* *}$ & $-3.904^{* *}$ \\
\hline OSECV & 21426.345 & 14.15311 .68 & $108.122 .7971^{* *}$ & $10.813^{* *}$ & $1327.7^{* *}$ & $-3.791^{* *}$ \\
\hline RTSCV & 21439.010 & 19.94217 .8 & $137.101 .8442^{* *}$ & $4.0907^{* *}$ & $271.78^{* *}$ & $-4.990^{* *}$ \\
\hline & \multicolumn{6}{|c|}{ Oil-Importing Countries } \\
\hline Returns & & & & & & \\
\hline$\Delta \ln (\mathrm{SSE})$ & 2140.0061 & $0.0821-0.2244$ & $0.26420 .3352^{*}$ & 0.4194 & 5.5767 & $-13.55^{* *}$ \\
\hline$\Delta \ln (\mathrm{IBEX} 35)$ & 2140.0037 & $0.0639-0.2361$ & $0.1595-0.6319^{* *}$ & $1.1885^{* *}$ & $26.838^{* *}$ & $-13.64^{* *}$ \\
\hline$\Delta \ln (\mathrm{CAC} 40)$ & 2140.0035 & $0.0610-0.2533$ & $0.1205-1.0182^{* *}$ & $1.9321^{* *}$ & $70.265^{* *}$ & $-13.34^{* *}$ \\
\hline$\Delta \ln (\mathrm{DAX} 30)$ & $214 \quad 0.0059$ & $0.0670-0.2714$ & $0.1674-0.7328^{* *}$ & $1.6925^{* *}$ & $44.693^{* *}$ & $-13.32^{* *}$ \\
\hline$\Delta \ln ($ FTSEITA $)$ & $214 \quad 0.0002$ & $0.0663-0.2597$ & $0.2328-0.4310^{* *}$ & $1.6908^{* *}$ & $32.119^{* *}$ & $-13.89 * *$ \\
\hline$\Delta \ln (\mathrm{NIKKEI} 225)$ & $214-0.0010$ & $0.0663-0.2089$ & $0.1965-0.2930$ & $0.8285^{*}$ & $9.1839^{*}$ & $-14.99 * *$ \\
\hline$\Delta \ln (\mathrm{FTSE} 100)$ & $214 \quad 0.0027$ & $0.0519-0.2704$ & $0.1255-1.2230^{* *}$ & $3.4775^{* *}$ & $161.18^{* *}$ & $-13.91^{* *}$ \\
\hline$\Delta \ln (\mathrm{S} \& \mathrm{P} 500)$ & $214 \quad 0.0049$ & $0.0478-0.2729$ & $0.1189-1.1524^{* *}$ & $4.5503^{* *}$ & $231.99^{* *}$ & $-14.39 * *$ \\
\hline \multicolumn{7}{|l|}{ Realised Volatility } \\
\hline SSERV & 21423.920 & 11.7047 .0870 & $82.4261 .4583^{* *}$ & $2.7164^{* *}$ & $145.61^{* *}$ & $-8.594^{* *}$ \\
\hline IBEX35RV & 21423.389 & 12.7143 .2046 & $99.4671 .9250^{* *}$ & $6.6881^{* *}$ & $545.90^{* *}$ & $-6.133^{* *}$ \\
\hline CAC40RV & 21422.681 & 12.3195 .3115 & $99.4532 .1910^{* *}$ & $7.9025^{* *}$ & $748.46^{* *}$ & $-5.788 * *$ \\
\hline DAX30RV & 21423.325 & 12.5494 .7649 & $90.9011 .7591^{* *}$ & $4.7469^{* *}$ & $320.02^{* *}$ & $-5.885 * *$ \\
\hline FTSEITARV & 21423.446 & 12.9344 .6273 & $96.7091 .8891^{* *}$ & $5.6263^{* *}$ & $421.02^{* *}$ & $-6.263^{* *}$ \\
\hline NIKKEI225RV & 21423.152 & 10.5582 .3874 & $94.1512 .1821^{* *}$ & $9.6313^{* *}$ & $1024.9^{* *}$ & $-8.408^{* *}$ \\
\hline FTSE100RV & 21418.753 & 11.1313 .3155 & $101.962 .9811^{* *}$ & $15.506^{* *}$ & $2529.7^{* *}$ & $-6.091^{* *}$ \\
\hline S\&P500RV & 21417.442 & 10.1056 .5368 & $82.9232 .6828^{* *}$ & $4.5503^{* *}$ & $231.99^{* *}$ & $-5.677^{* *}$ \\
\hline \multicolumn{7}{|l|}{ Conditional Volatility } \\
\hline SSECV & 21427.692 & 9.419315 .9 & $72.8901 .3310^{* *}$ & $2.0001^{* *}$ & $99.315^{* *}$ & $-5.800 * *$ \\
\hline IBEX $35 \mathrm{CV}$ & $214 \quad 24.430$ & 10.98910 .83 & $77.7201 .7970^{* *}$ & $4.7329 * *$ & $316.38^{* *}$ & $-4.550 * *$ \\
\hline CAC40CV & 21423.572 & 10.39012 .28 & $77.9902 .1600^{* *}$ & $6.6607^{* *}$ & $564.61^{* *}$ & $-4.187^{* *}$ \\
\hline DAX30CV & 21424.287 & 10.9519 .76 & $73.8501 .7473^{* *}$ & $3.9558^{* *}$ & $249.59^{* *}$ & $-4.362 * *$ \\
\hline FTSEITACV & 21424.660 & 11.15410 .61 & $78.9001 .8456^{* *}$ & $4.5224^{* *}$ & $305.28^{* *}$ & $-4.592^{* *}$ \\
\hline NIKKEI225CV & 21424.246 & $7.745 \quad 14.54$ & $68.1702 .2301^{* *}$ & $7.8911^{* *}$ & $736.03^{* *}$ & $-5.773^{* *}$ \\
\hline FTSE100CV & 21419.506 & 9.50829 .38 & $81.9002 .9814^{* *}$ & $13.460^{* *}$ & $1941.6^{* *}$ & $-4.442^{* *}$ \\
\hline S\&P500CV & 21418.125 & 9.17647 .78 & $73.2302 .7666^{* *}$ & $11.337^{* *}$ & $1425.6^{* *}$ & $-4.495^{* *}$ \\
\hline \multicolumn{7}{|l|}{ Implied Volatility } \\
\hline $\mathrm{VCAC}$ & 16324.206 & 9.261711 .483 & $64.3301 .4167^{* *}$ & $2.5517^{* *}$ & $101.77^{* *}$ & $-3.923^{* *}$ \\
\hline VDAX & 21424.842 & 10.16810 .580 & $64.1101 .4276^{* *}$ & $1.8293^{* *}$ & $80.492^{* *}$ & $-3.641^{* *}$ \\
\hline VXJ & 18726.428 & 9.509013 .580 & $76.3502 .4537^{* *}$ & $7.9706^{* *}$ & $613.29^{* *}$ & $-5.530 * *$ \\
\hline VFTSE & 16321.286 & 9.332210 .294 & $63.2601 .7085^{* *}$ & $3.8682^{* *}$ & $186.47^{* *}$ & $-4.060 * *$ \\
\hline VIX & 21421.616 & 8.6736010 .050 & $69.2502 .1415^{* *}$ & $7.2211^{* *}$ & $493.42^{* *}$ & $-3.945^{* *}$ \\
\hline
\end{tabular}

Note: ADF denotes Augmented Dickey Fuller tests with 5\% and 1\% critical values of -2.88 and -3.46 , respectively. ${ }^{*}$ and $* *$ indicate significance at $5 \%$ and $1 \%$ level, respectively. 
Table 2: Oil price shocks and stock market returns, connectedness table (1995:09 - 2013:07)

\begin{tabular}{|c|c|c|c|c|c|c|c|c|c|c|}
\hline \multirow[b]{3}{*}{ To (i) } & \multicolumn{5}{|c|}{$\overline{\mathrm{CAN}}$} & \multicolumn{5}{|c|}{$\overline{\mathrm{CHN}}$} \\
\hline & \multicolumn{5}{|c|}{ From $(j)$} & \multicolumn{5}{|c|}{ From $(j)$} \\
\hline & $\mathrm{SS}$ & ADS & OSS & SMR & From others & $\mathrm{SS}$ & ADS & OSS & SMR & From others \\
\hline SS & 78.6 & 6.4 & 7.7 & 7.3 & 21.4 & 84.0 & 7.4 & 6.0 & 2.6 & 16.0 \\
\hline ADS & 2.2 & 78.2 & 3.3 & 16.4 & 21.8 & 1.9 & 57.6 & 3.3 & 37.2 & 42.4 \\
\hline OSS & 6.1 & 7.9 & 76.4 & 9.7 & 23.6 & 6.8 & 7.2 & 78.0 & 7.9 & 22.0 \\
\hline SMR & 7.8 & 8.8 & 15.9 & 67.5 & 32.5 & 3.2 & 2.0 & 4.8 & 89.9 & 10.1 \\
\hline Contr. to others & 16.1 & 23.0 & 26.9 & 33.4 & Tot. Connectedness & 12.0 & 16.7 & 14.0 & 47.7 & Tot. Connectedness \\
\hline Contr. incl. own & 94.7 & 101.2 & 103.2 & 100.9 & Measure $=24.8 \%$ & 95.9 & 74.3 & 92.1 & 137.7 & Measure $=22.6 \%$ \\
\hline \multirow[t]{3}{*}{ Net connectedness } & -5.3 & 1.2 & 3.3 & 0.9 & & -4 & -25.7 & -8 & 37.6 & \\
\hline & \multicolumn{5}{|c|}{ ESP } & \multicolumn{5}{|c|}{ FRA } \\
\hline & \multicolumn{5}{|c|}{ From $(j)$} & \multicolumn{5}{|c|}{ From $(j)$} \\
\hline To (i) & SS & $\mathrm{ADS}$ & OSS & SMR & From others & SS & ADS & OSS & SMR & From others \\
\hline SS & 81.6 & 7.2 & 6.4 & 4.8 & 18.4 & 81.8 & 6.4 & 6.6 & 5.2 & 18.2 \\
\hline ADS & 2.1 & 85.2 & 4.4 & 8.3 & 14.8 & 2.6 & 82.2 & 3.9 & 11.4 & 17.8 \\
\hline OSS & 6.0 & 6.8 & 80.7 & 6.4 & 19.3 & 6.3 & 7.6 & 79.8 & 6.3 & 20.2 \\
\hline SMR & 8.8 & 7.6 & 2.6 & 81.0 & 19.0 & 7.7 & 7.4 & 8.4 & 76.5 & 23.5 \\
\hline Contr. to others & 16.9 & 21.6 & 13.3 & 19.5 & Tot. Connectedness & 16.6 & 21.4 & 18.9 & 22.9 & Tot. Connectedness \\
\hline Contr. incl. own & 98.6 & 106.8 & 94.1 & 100.5 & Measure $=17.9 \%$ & 98.4 & 103.6 & 98.7 & 99.4 & Measure $=19.9 \%$ \\
\hline \multirow[t]{3}{*}{ Net connectedness } & -1.5 & 6.8 & 6 & 0.5 & & -1.6 & 3.6 & -1.3 & -0.6 & \\
\hline & \multicolumn{5}{|c|}{ GER } & \multicolumn{5}{|c|}{ ITA } \\
\hline & \multicolumn{5}{|c|}{ From $(j)$} & & & & om $(j)$ & \\
\hline To (i) & SS & ADS & OSS & SMR & From others & SS & ADS & OSS & SMR & From others \\
\hline $\mathrm{SS}$ & 83.6 & 5.9 & 6.0 & 4.5 & 16.4 & 82.1 & 6.3 & 6.9 & 4.7 & 17.9 \\
\hline ADS & 2.5 & 83.1 & 3.8 & 10.6 & 16.9 & 2.8 & 87.1 & 5.3 & 4.8 & 12.9 \\
\hline OSS & 6.9 & 7.7 & 78.7 & 6.7 & 21.3 & 6.0 & 6.9 & 79.9 & 7.2 & 20.1 \\
\hline SMR & 9.2 & 7.0 & 4.0 & 79.9 & 20.1 & 11.9 & 8.5 & 4.6 & 74.9 & 25.1 \\
\hline Contr. to others & 18.6 & 20.6 & 13.8 & 21.8 & Tot. Connectedness & 20.7 & 21.7 & 16.9 & 16.7 & Tot. Connectedness \\
\hline Contr. incl. own & 102.2 & 103.6 & 92.5 & 101.7 & Measure $=18.7 \%$ & 102.8 & 108.7 & 96.8 & 91.6 & Measure $=19.0 \%$ \\
\hline Net connectedness & 2.2 & 3.7 & -7.5 & 1.7 & & 2.8 & 8.8 & -3.2 & -8.4 & \\
\hline & & & & JPN & & & & & NOR & \\
\hline & & & & $o m(j)$ & & & & & om $(j)$ & \\
\hline To (i) & SS & ADS & OSS & SMR & From others & SS & ADS & OSS & SMR & From others \\
\hline SS & 83.4 & 5.1 & 5.5 & 5.9 & 16.6 & 82.9 & 9.2 & 6.6 & 1.3 & 17.1 \\
\hline ADS & 2.9 & 81.2 & 5.6 & 10.3 & 18.8 & 2.6 & 77.2 & 5.4 & 14.8 & 22.8 \\
\hline OSS & 6.3 & 6.9 & 79.8 & 7.0 & 20.2 & 6.5 & 9.8 & 79.6 & 4.1 & 20.4 \\
\hline SMR & 3.9 & 9.1 & 4.8 & 82.2 & 17.8 & 7.8 & 4.3 & 1.8 & 86.1 & 13.0 \\
\hline Contr. to others & 13.0 & 21.1 & 16.0 & 23.2 & Tot. Connectedness & 18.8 & 51.9 & 10.5 & 22.0 & Tot. Connectedness \\
\hline Contr. incl. own & 96.5 & 102.4 & 95.8 & 105.4 & Measure $=18.3 \%$ & 90.8 & 139.1 & 83.6 & 86.5 & Measure $=25.8 \%$ \\
\hline Net connectedness & -3.6 & 2.3 & -4.2 & 5.4 & & 1.7 & 29.1 & -9.9 & 9 & \\
\hline & & & & RUS & & & & & UK & \\
\hline & & & & $o m(j)$ & & & & & om $(j)$ & \\
\hline To (i) & $\mathrm{SS}$ & ADS & OSS & SMR & From others & $\mathrm{SS}$ & ADS & OSS & SMR & From others \\
\hline $\mathrm{SS}$ & 77.7 & 11.1 & 5.2 & 6.1 & 22.3 & 82.9 & 7.6 & 6.6 & 2.9 & 17.1 \\
\hline ADS & 2.3 & 76.7 & 2.9 & 18.1 & 23.3 & 2.5 & 88.6 & 3.8 & 5.1 & 11.4 \\
\hline OSS & 8.5 & 9.2 & 71.3 & 10.9 & 28.7 & 6.6 & 7.5 & 79.3 & 6.5 & 20.7 \\
\hline SMR & 1.4 & 4.0 & 1.6 & 93.0 & 7.0 & 9.4 & 8.2 & 7.9 & 74.6 & 25.4 \\
\hline Contr. to others & 18.0 & 18.7 & 20.8 & 23.3 & Tot. Connectedness & 18.5 & 23.3 & 18.3 & 14.6 & Tot. Connectedness \\
\hline Contr. incl. own & 99.9 & 103.6 & 96.5 & 100.1 & Measure $=20.2 \%$ & 101.4 & 111.9 & 97.6 & 89.1 & Measure $=18.7 \%$ \\
\hline Net connectedness & -4.3 & -4.6 & -7.9 & 16.3 & & 1.4 & 11.9 & -2.4 & -10.8 & \\
\hline & & & & US & & & & & & \\
\hline & & & & om $(j)$ & & & & & & \\
\hline To (i) & SS & ADS & OSS & SMR & From others & & & & & \\
\hline SS & 79.9 & 7.7 & 6.4 & 6.0 & 20.1 & & & & & \\
\hline ADS & 2.5 & 91.2 & 4.0 & 2.3 & 8.8 & & & & & \\
\hline OSS & 6.6 & 8.6 & 76.6 & 8.2 & 23.4 & & & & & \\
\hline SMR & 9.5 & 9.1 & 6.6 & 74.8 & 25.2 & & & & & \\
\hline Contr. to others & 18.6 & 25.4 & 17.0 & 16.4 & Tot. Connectedness & & & & & \\
\hline Contr. incl. own & 98.5 & 116.6 & 93.7 & 91.2 & Measure $=19.4 \%$ & & & & & \\
\hline Net connectedness & -1.5 & 16.6 & -6.4 & -8.8 & & & & & & \\
\hline
\end{tabular}

Note: Connectedness measures, given by Equations (2)-(6), calculated from variance decompositions based on 12-step-ahead forecasts. 
Table 3: Oil price shocks and stock market realised volatility, connectedness table (1995:09 - 2013:07)

\begin{tabular}{|c|c|c|c|c|c|c|c|c|c|c|}
\hline \multirow[b]{3}{*}{ To $(i)$} & \multicolumn{5}{|c|}{$\overline{\mathrm{CAN}}$} & \multicolumn{5}{|c|}{ CHN } \\
\hline & \multicolumn{5}{|c|}{ From $(j)$} & \multicolumn{5}{|c|}{ From $(j)$} \\
\hline & $\mathrm{SS}$ & ADS & OSS & SMRV & From others & $\mathrm{SS}$ & ADS & OSS & SMRV & From others \\
\hline SS & 79.0 & 8.1 & 7.3 & 5.6 & 21.0 & 82.4 & 7.6 & 6.0 & 4.0 & 17.6 \\
\hline ADS & 2.0 & 89.4 & 4.1 & 4.5 & 10.6 & 2.6 & 92.3 & 3.6 & 1.5 & 7.7 \\
\hline OSS & 6.9 & 8.4 & 75.3 & 9.5 & 24.7 & 5.1 & 10.1 & 80.7 & 4.0 & 19.3 \\
\hline SMRV & 4.5 & 4.2 & 10.9 & 80.3 & 19.7 & 10.2 & 6.0 & 2.6 & 81.3 & 18.7 \\
\hline Contr. to others & 13.4 & 20.8 & 22.4 & 19.5 & Tot. Connectedness & 17.9 & 23.7 & 12.2 & 9.4 & Tot. Connectedness \\
\hline Contr. incl. own & 92.4 & 110.2 & 97.6 & 99.8 & Measure $=19.0 \%$ & 100.4 & 116.0 & 92.9 & 90.7 & Measure $=15.8 \%$ \\
\hline \multirow[t]{3}{*}{ Net connectedness } & -7.6 & 10.2 & -2.3 & -0.2 & & 0.3 & 16.0 & -7.1 & -9.3 & \\
\hline & \multicolumn{5}{|c|}{ ESP } & \multicolumn{5}{|c|}{ FRA } \\
\hline & \multicolumn{5}{|c|}{ From $(j)$} & \multicolumn{5}{|c|}{ From $(j)$} \\
\hline To $(i)$ & SS & ADS & OSS & SMRV & From others & $\mathrm{SS}$ & ADS & OSS & SMRV & From others \\
\hline $\mathrm{SS}$ & 81.8 & 6.7 & 6.9 & 4.6 & 18.2 & 81.2 & 7.3 & 6.9 & 4.5 & 18.8 \\
\hline ADS & 2.8 & 76.2 & 3.6 & 17.4 & 23.8 & 2.7 & 85.5 & 2.5 & 9.3 & 14.5 \\
\hline OSS & 6.5 & 7.1 & 74.9 & 11.4 & 25.1 & 6.7 & 8.6 & 72.4 & 12.3 & 27.6 \\
\hline SMRV & 2.4 & 3.7 & 7.4 & 86.5 & 13.5 & 8.3 & 5.9 & 6.0 & 79.8 & 20.2 \\
\hline Contr. to others & 11.7 & 17.5 & 17.9 & 33.5 & Tot. Connectedness & 17.6 & 21.8 & 15.4 & 26.2 & Tot. Connectedness \\
\hline Contr. incl. own & 93.5 & 93.7 & 92.8 & 120.0 & Measure $=20.1 \%$ & 98.8 & 107.3 & 87.8 & 106.0 & Measure $=20.2 \%$ \\
\hline \multirow[t]{3}{*}{ Net connectedness } & -6.5 & -6.3 & -7.2 & 20 & & -1.2 & 7.3 & -12.2 & 6 & \\
\hline & \multicolumn{5}{|c|}{ GER } & \multicolumn{5}{|c|}{ ITA } \\
\hline & \multicolumn{5}{|c|}{ From $(j)$} & & & & rom $(j)$ & \\
\hline To (i) & SS & ADS & OSS & SMRV & From others & SS & ADS & OSS & SMRV & From others \\
\hline $\mathrm{SS}$ & 82.2 & 7.0 & 6.8 & 4.0 & 17.8 & 83.5 & 6.9 & 6.5 & 3.1 & 16.5 \\
\hline ADS & 2.5 & 88.3 & 2.7 & 6.4 & 11.7 & 3.7 & 74.9 & 3.8 & 17.6 & 25.1 \\
\hline OSS & 7.0 & 8.2 & 72.9 & 11.9 & 27.1 & 6.3 & 6.4 & 76.6 & 10.8 & 23.4 \\
\hline SMRV & 9.3 & 6.7 & 4.4 & 79.6 & 20.4 & 6.0 & 6.2 & 7.8 & 80.0 & 20.0 \\
\hline Contr. to others & 18.8 & 22.0 & 14.0 & 22.2 & Tot. Connectedness & 16.0 & 19.5 & 18.2 & 31.4 & Tot. Connectedness \\
\hline Contr. incl. own & 101.0 & 110.3 & 86.9 & 101.8 & Measure $=19.3 \%$ & 99.5 & 94.3 & 94.7 & 111.4 & Measure $=21.3 \%$ \\
\hline Net connectedness & 1.0 & 10.3 & -13.1 & 1.8 & & -0.5 & -5.6 & -5.2 & 11.4 & \\
\hline & & & & JPN & & & & & NOR & \\
\hline & & & & rom $(j)$ & & & & & rom $(j)$ & \\
\hline To (i) & SS & ADS & OSS & SMRV & From others & SS & ADS & OSS & SMRV & From others \\
\hline SS & 78.4 & 7.5 & 5.8 & 8.3 & 21.6 & 82.5 & 7.5 & 6.6 & 3.4 & 17.5 \\
\hline ADS & 1.7 & 90.0 & 2.7 & 5.6 & 10.0 & 2.2 & 86.9 & 3.8 & 7.2 & 13.1 \\
\hline OSS & 7.7 & 9.9 & 73.4 & 9.0 & 26.6 & 6.2 & 7.4 & 71.5 & 15.0 & 28.5 \\
\hline SMRV & 3.5 & 8.5 & 6.3 & 81.7 & 18.3 & 6.9 & 4.8 & 8.4 & 79.9 & 20.1 \\
\hline Contr. to others & 12.9 & 25.9 & 14.8 & 22.9 & Tot. Connectedness & 15.3 & 19.6 & 18.8 & 25.6 & Tot. Connectedness \\
\hline Contr. incl. own & 91.3 & 115.9 & 88.3 & 104.6 & Measure $=19.1 \%$ & 97.8 & 106.5 & 90.3 & 105.5 & Measure $=19.8 \%$ \\
\hline Net connectedness & -8.7 & 15.9 & -11.8 & 4.6 & & -2.2 & 6.5 & -9.7 & 5.5 & \\
\hline & & & & RUS & & & & & UK & \\
\hline & & & & $\operatorname{rom}(j)$ & & & & & rom $(j)$ & \\
\hline To (i) & $\mathrm{SS}$ & ADS & OSS & SMRV & From others & $\mathrm{SS}$ & ADS & OSS & SMRV & From others \\
\hline $\mathrm{SS}$ & 82.5 & 8.3 & 7.3 & 1.9 & 17.5 & 82.1 & 7.6 & 6.8 & 3.5 & 17.9 \\
\hline ADS & 2.5 & 85.9 & 4.2 & 7.4 & 14.1 & 2.7 & 86.6 & 3.0 & 7.7 & 13.4 \\
\hline OSS & 6.0 & 6.1 & 76.8 & 11.1 & 23.2 & 6.2 & 8.3 & 72.9 & 12.6 & 27.1 \\
\hline SMRV & 2.8 & 2.8 & 2.8 & 91.6 & 8.4 & 10.2 & 5.3 & 6.9 & 77.6 & 22.4 \\
\hline Contr. to others & 11.3 & 17.2 & 14.2 & 20.5 & Tot. Connectedness & 19.1 & 21.2 & 16.8 & 23.7 & Tot. Connectedness \\
\hline Contr. incl. own & 93.8 & 103.1 & 91.0 & 112.1 & Measure $=15.8 \%$ & 101.2 & 107.8 & 89.7 & 101.3 & Mesasure $=20.2 \%$ \\
\hline Net connectedness & -6.2 & 3.1 & -9.0 & 12.1 & & 1.2 & 7.8 & -10.3 & 1.3 & \\
\hline & & & & US & & & & & & \\
\hline & & & & rom $(j)$ & & & & & & \\
\hline To (i) & SS & $\mathrm{ADS}$ & OSS & SMRV & From others & & & & & \\
\hline SS & 78.4 & 7.8 & 7.7 & 6.1 & 21.6 & & & & & \\
\hline ADS & 2.4 & 88.2 & 4.0 & 5.5 & 11.8 & & & & & \\
\hline OSS & 6.9 & 7.9 & 78.1 & 7.0 & 21.9 & & & & & \\
\hline SMRV & 11.4 & 4.4 & 10.2 & 73.9 & 26.1 & & & & & \\
\hline Contr. to others & 20.7 & 20.1 & 21.9 & 18.6 & Tot. Connectedness & & & & & \\
\hline Contr. incl. own & 99.1 & 108.3 & 100.0 & 92.6 & Measure $=20.4 \%$ & & & & & \\
\hline Net connectedness & -0.9 & 8.3 & 0.0 & -7.5 & & & & & & \\
\hline
\end{tabular}

Note: Connectedness measures, given by Equations (2)-(6), calculated from variance decompositions based on 12-step-ahead forecasts. 
Table 4: Oil price shocks and stock market implied volatility, connectedness table (1995:09 - 2013:07)

\begin{tabular}{|c|c|c|c|c|c|c|c|c|c|c|}
\hline \multirow[b]{3}{*}{ To (i) } & \multicolumn{5}{|c|}{ FRA } & \multicolumn{5}{|c|}{ GER } \\
\hline & \multicolumn{5}{|c|}{ From $(j)$} & \multicolumn{5}{|c|}{ From $(j)$} \\
\hline & $\mathrm{SS}$ & ADS & OSS & SMIV & From others & $\mathrm{SS}$ & ADS & OSS & SMIV & From others \\
\hline SS & 81.2 & 9.5 & 7.1 & 2.2 & 18.8 & 84.6 & 6.6 & 7.0 & 1.9 & 15.4 \\
\hline ADS & 2.6 & 91.8 & 4.0 & 1.6 & 8.2 & 3.1 & 90.7 & 4.1 & 2.1 & 9.3 \\
\hline OSS & 9.6 & 11.1 & 68.9 & 10.4 & 31.1 & 6.3 & 7.5 & 73.1 & 13.1 & 26.9 \\
\hline SMIV & 25.7 & 7.9 & 5.6 & 60.8 & 39.2 & 14.5 & 8.9 & 5.1 & 71.5 & 28.5 \\
\hline Contr. to others & 37.9 & 28.6 & 16.6 & 14.2 & Tot. Connectedness & 23.9 & 23.0 & 16.2 & 17.1 & Tot. Connectedness \\
\hline Contr. incl. own & 119.1 & 120.4 & 85.5 & 75.0 & Measure $=24.3 \%$ & 108.5 & 113.7 & 89.2 & 88.6 & Measure $=20.0 \%$ \\
\hline \multirow[t]{3}{*}{ Net connectedness } & 19.1 & 20.4 & -14.5 & -25.0 & & 8.5 & 13.7 & -10.7 & 11.4 & \\
\hline & \multicolumn{5}{|c|}{ JPN } & \multicolumn{5}{|c|}{ UK } \\
\hline & \multicolumn{5}{|c|}{ From $(j)$} & \multicolumn{5}{|c|}{ From $(j)$} \\
\hline To (i) & SS & $\mathrm{ADS}$ & OSS & SMIV & From others & $\mathrm{SS}$ & ADS & OSS & SMIV & From others \\
\hline SS & 77.5 & 7.7 & 7.4 & 7.4 & 22.5 & 76.6 & 10.3 & 7.3 & 5.8 & 23.4 \\
\hline $\mathrm{ADS}$ & 1.8 & 90.1 & 3.8 & 4.3 & 9.9 & 3.6 & 91.5 & 3.8 & 1.1 & 8.5 \\
\hline OSS & 6.7 & 9.7 & 79.6 & 4.0 & 20.4 & 8.8 & 11.4 & 67.5 & 12.3 & 32.5 \\
\hline SMIV & 8.8 & 25.9 & 10.4 & 54.9 & 45.1 & 31.9 & 8.5 & 5.5 & 54.1 & 45.9 \\
\hline Contr. to others & 17.4 & 43.3 & 21.6 & 15.7 & Tot. Connectedness & 44.2 & 30.2 & 16.6 & 19.2 & Tot. Connectedness \\
\hline Contr. incl. own & 94.9 & 133.3 & 101.2 & 70.6 & Measure $=24.5 \%$ & 120.8 & 121.8 & 84.1 & 73.3 & Measure $=27.6 \%$ \\
\hline Net connectedness & -6.5 & -6.3 & -7.2 & 20 & & -1.2 & 7.3 & -12.2 & 6 & \\
\hline \multicolumn{11}{|c|}{$\overline{U S}$} \\
\hline & \multicolumn{5}{|c|}{ From $(j)$} & & & & & \\
\hline To (i) & $\mathrm{SS}$ & ADS & OSS & SMIV & From others & & & & & \\
\hline $\mathrm{SS}$ & 80.7 & 7.4 & 7.9 & 4.0 & 19.3 & & & & & \\
\hline ADS & 2.6 & 90.7 & 4.3 & 2.4 & 9.3 & & & & & \\
\hline OSS & 6.0 & 8.2 & 75.7 & 10.0 & 24.3 & & & & & \\
\hline SMIV & 8.2 & 9.8 & 10.8 & 71.2 & 28.8 & & & & & \\
\hline Contr. to others & 16.8 & 25.5 & 23.0 & 16.5 & Tot. Connectedness & & & & & \\
\hline Contr. incl. own & 97.5 & 116.1 & 98.7 & 87.7 & Measure $=20.4 \%$ & & & & & \\
\hline Net connectedness & -0.9 & 8.3 & 0.0 & -7.5 & & & & & & \\
\hline
\end{tabular}

Note: Connectedness measures, given by Equations (2)-(6), calculated from variance decompositions based on 12-step-ahead forecasts. 


\section{Online Appendix}

\section{A.1. Gross directional connectedness between oil price shocks and stock market returns}

The time-varying gross directional connectedness from (to) each variable to (from) all others are defined in equations (6)-(7). The gross directional connectedness from (to) each variable to (from) all others are presented in Figures A.1 and A.2, respectively.

[Insert Figures A.1 and A.2 around here]

Starting with the supply-side shocks (SS), we observe a structural break in their contribution to connectedness in the post-2009 period. In particular, low connectedness exists until 2009, whereas an increasing pattern in shocks deriving from oil-supply shocks is evident thereafter, reaching a peak towards the end of the Great Recession. Notably, the peak for all European countries of our sample is evident almost two years later, at the end of 2010, i.e. immediately after the outbreak of the Eurozone debt crisis. A similar behaviour (although from the reverse angle) is observed in terms of shocks towards the supply-side shocks. These gross directional connectedness measures exhibit a stable pattern at about $20 \%$ level until 2009 (where a peak in reached), while a decline is observed thereafter (at the levels of about 10-15\%).

A structural break is also evident in the gross directional connectedness from and to aggregate demand shocks (ADS). More specifically, gross directional connectedness from aggregate demand shocks are high until 2009 (at about 25-50\% level), when they reach their peak, whereas a continued decline is observed in the post-Great Recession period (the only exception is Russia). In terms of the gross directional connectedness to aggregate demand shocks we notice that they are volatile and heterogeneous among countries until 2009, whereas a stable and increasing pattern is noticeable thereafter.

Furthermore, connectedness associated with oil-specific demand shocks (OSS) appears to decline remarkably during the peak years of the Great Recession with the exception of Japan. On the other hand, for all countries of our sample, the magnitude of shocks received by oil-specific demand shocks is relatively stable, at about $20 \%$.

Considering the connectedness running from stock market returns (SMR) shocks, we observe that they tend to fluctuate at the level of about $25 \%$ reaching, though, a trough in 2009 (although the reverse holds true for Russia). At the other end of the spectrum, stock market returns receive shocks at a rather stable pattern, reaching a spike at the heart of the Great Recession (with the exception of Italy). 
Figure A.1: Directional spillovers FROM oil price shocks and stock market returns to all others

Oil Exporting Countries
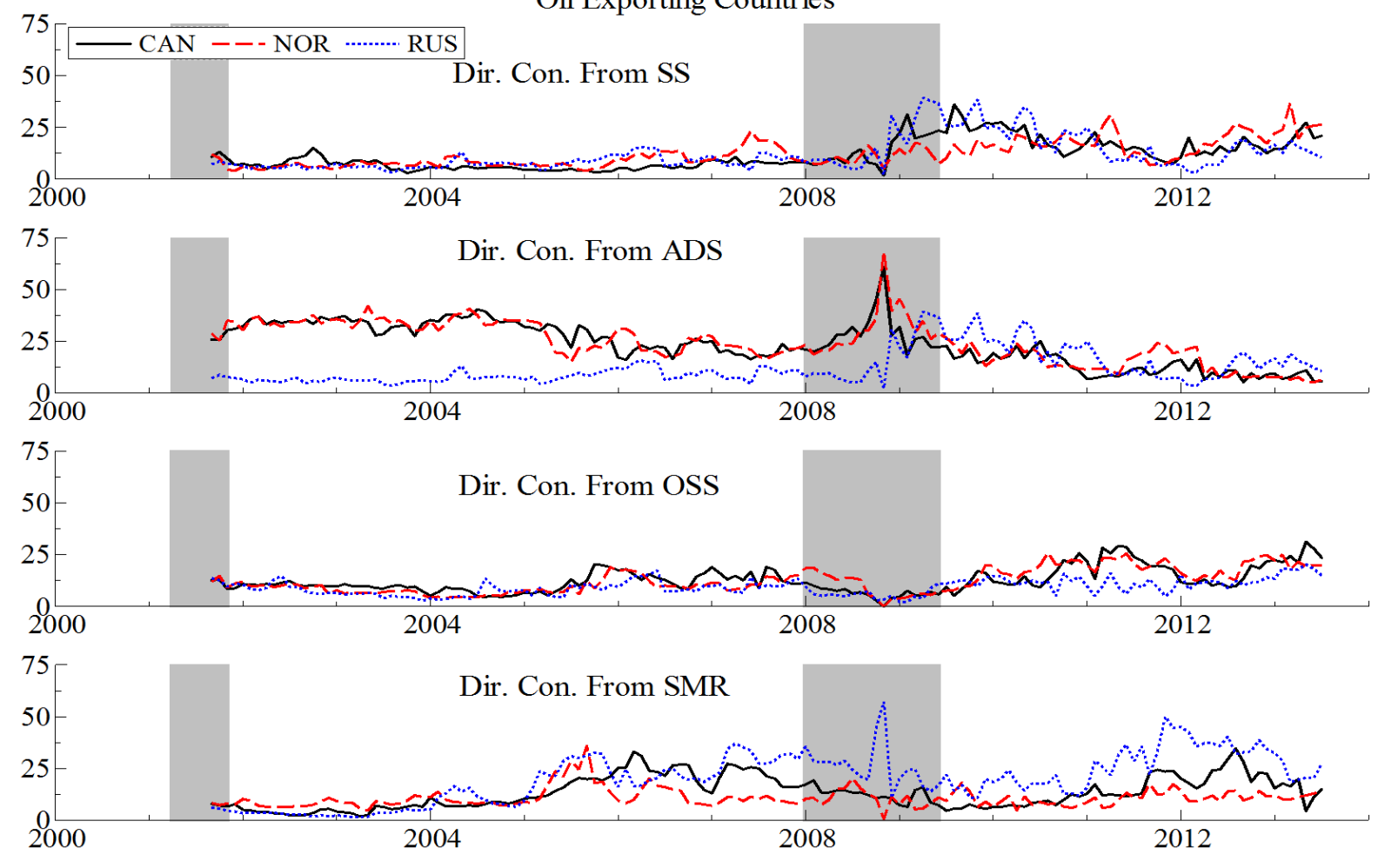

Oil Importing Countries

Figure A.2: Directional spillovers $T O$ oil price shocks and stock market returns from all others

Oil Exporting Countries


Oil Importing Countries



\section{A.2. Gross directional connectedness between oil price shocks and stock market (realized and implied) volatility}

This section presents the gross directional connectedness from (to) each variable to (from) all others for both the realized and implied volatilities. The gross directional connectedness measures based on the realized volatility are presented in Figures A.3 and A.4, respectively.

[Insert Figures A.3 and A.4 around here]

Starting with the supply-side shocks (SS), these appear to contribute considerably in the years during the Great Recession for the oil-importing countries and during 2010-2011 for the oil-exporting countries. We notice, though, that some exemptions exist among the net oil-importing countries (i.e. China, Japan and the US), as a peak is reached in these countries immediately after the period of the Great Recession, resembling the connectedness patterns of the net oil-exporting countries. By contrast, supply-side shocks receive shocks mainly in the pre-Great Recession period.

Turning to aggregate demand shocks (ADS), these contribute considerably to shocks in all other variables in the pre-Great Recession period. Furthermore, with the exception of Russia, the UK and the US, shocks generated by aggregate demand shocks attain a peak at the heart of the financial crisis. On the other hand, aggregate demand shocks appear to receive shocks throughout the period of study without following a stable path.

As far as the oil-specific demand shocks (OSS) are concerned, they seem to contribute more in the years that followed the Great Recession, while all other variables tend to instigate shocks to oil-specific demand shocks at a rather stable pace throughout the period of study, reaching a peak during the years of the Great Recession.

Considering the stock market realized volatility (SMRV) shocks, results regarding effects from this variable to all other variables seem to be country specific. Nonetheless, we note that in all European countries a peak is reached in the years immediately before the onset of the Great Recession. Turning to shocks exerted on stock market realized volatility, these appear to be rather stable (at about 10-20\% level) throughout the period of study, reaching a peak at the heart of the Great Recession.

Finally, we notice that the gross directional connectedness measures based on implied volatilities (see, Figures A.5 and A.6) are exhibiting a very similar behaviour with those based on the realized volatility. 
Figure A.3: Directional spillovers FROM oil price shocks and stock market realised volatility to all others

Figure A.4: Directional spillovers $T O$ oil price shocks and stock market realised volatility from all others

Oil Exporting Countries
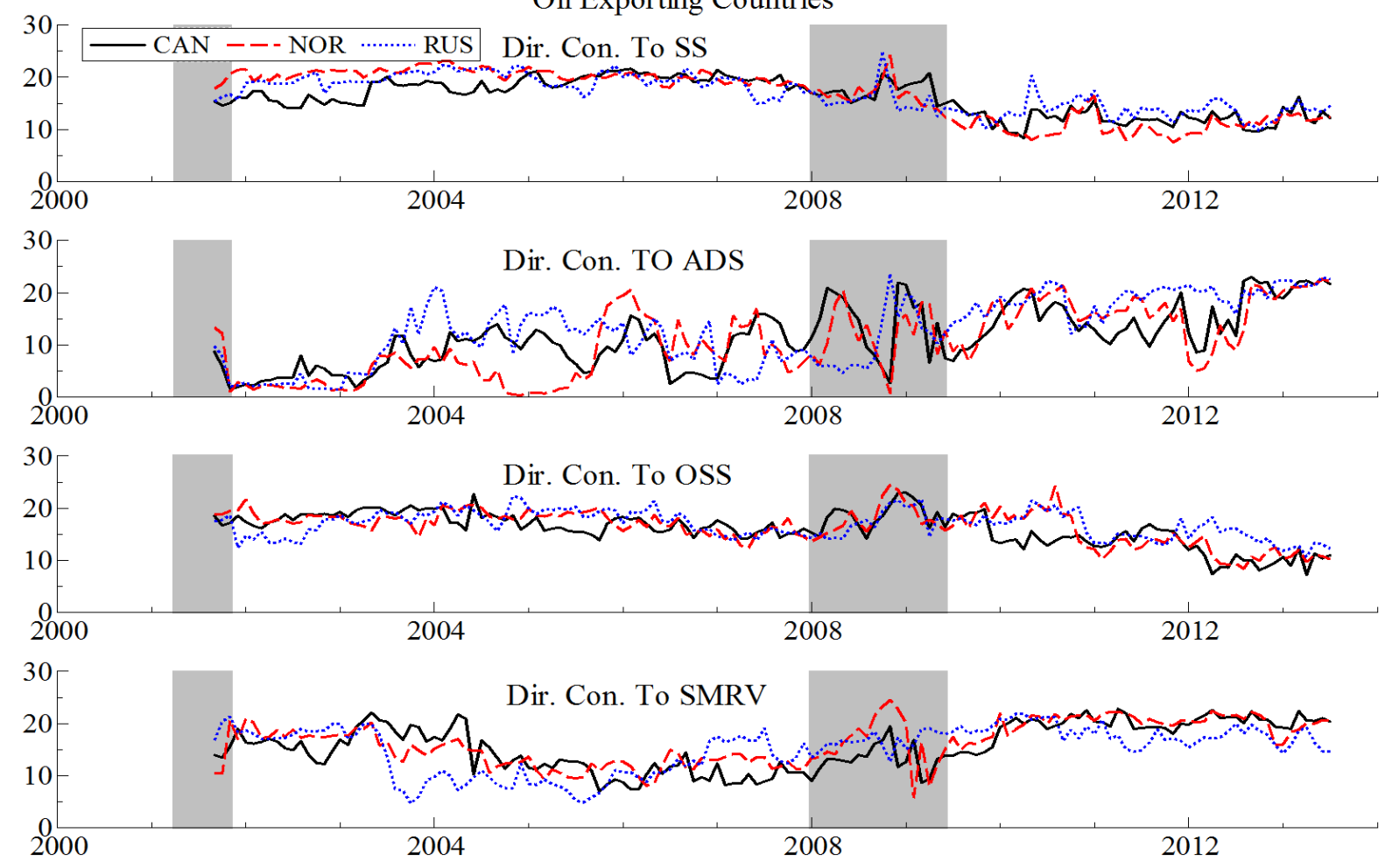

Oil Importing Countries
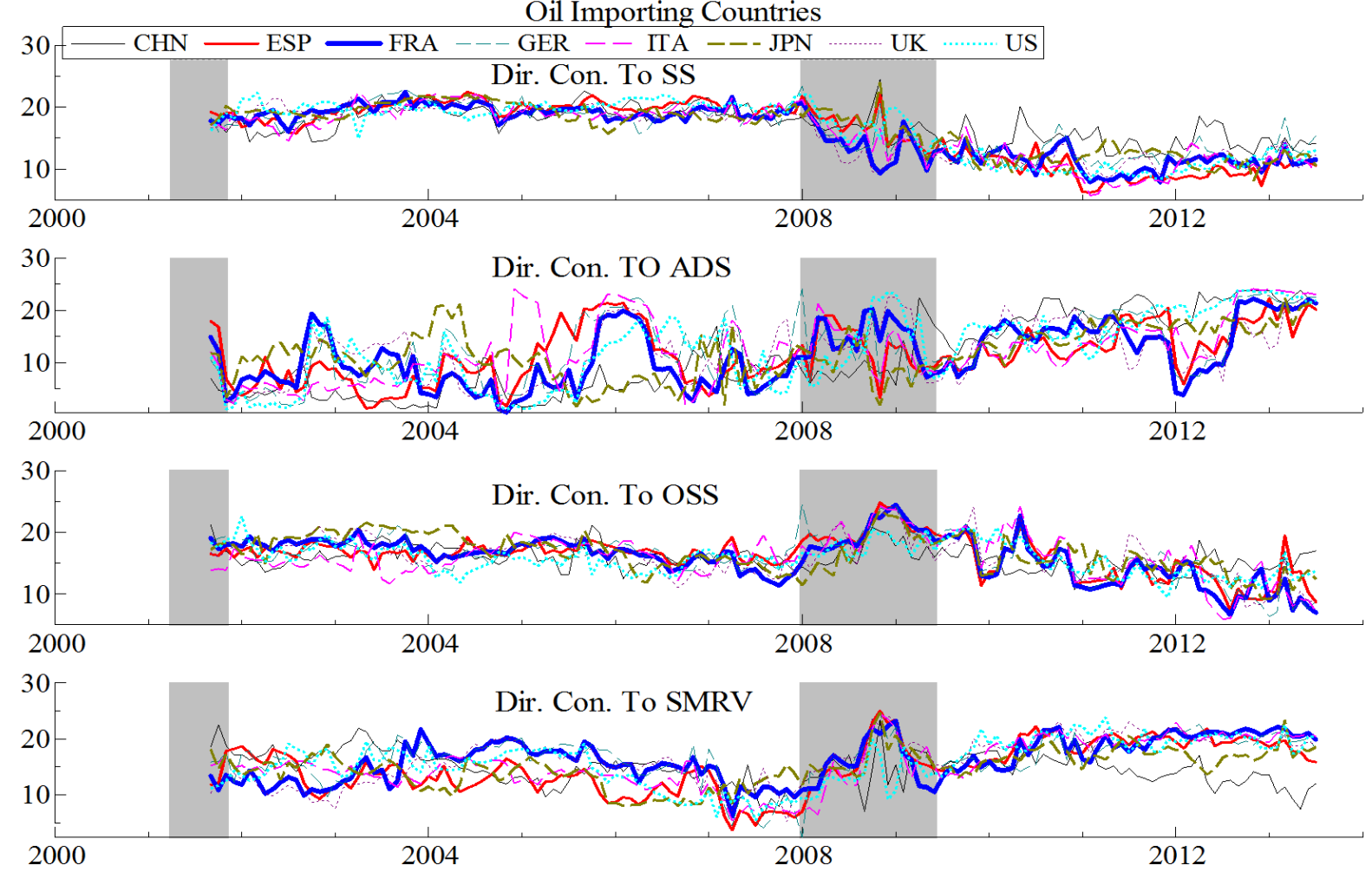
Figure A.5: Directional spillovers FROM oil price shocks and stock market implied volatility to all others

Figure A.6: Directional spillovers $T O$ oil price shocks and stock market implied volatility from all others
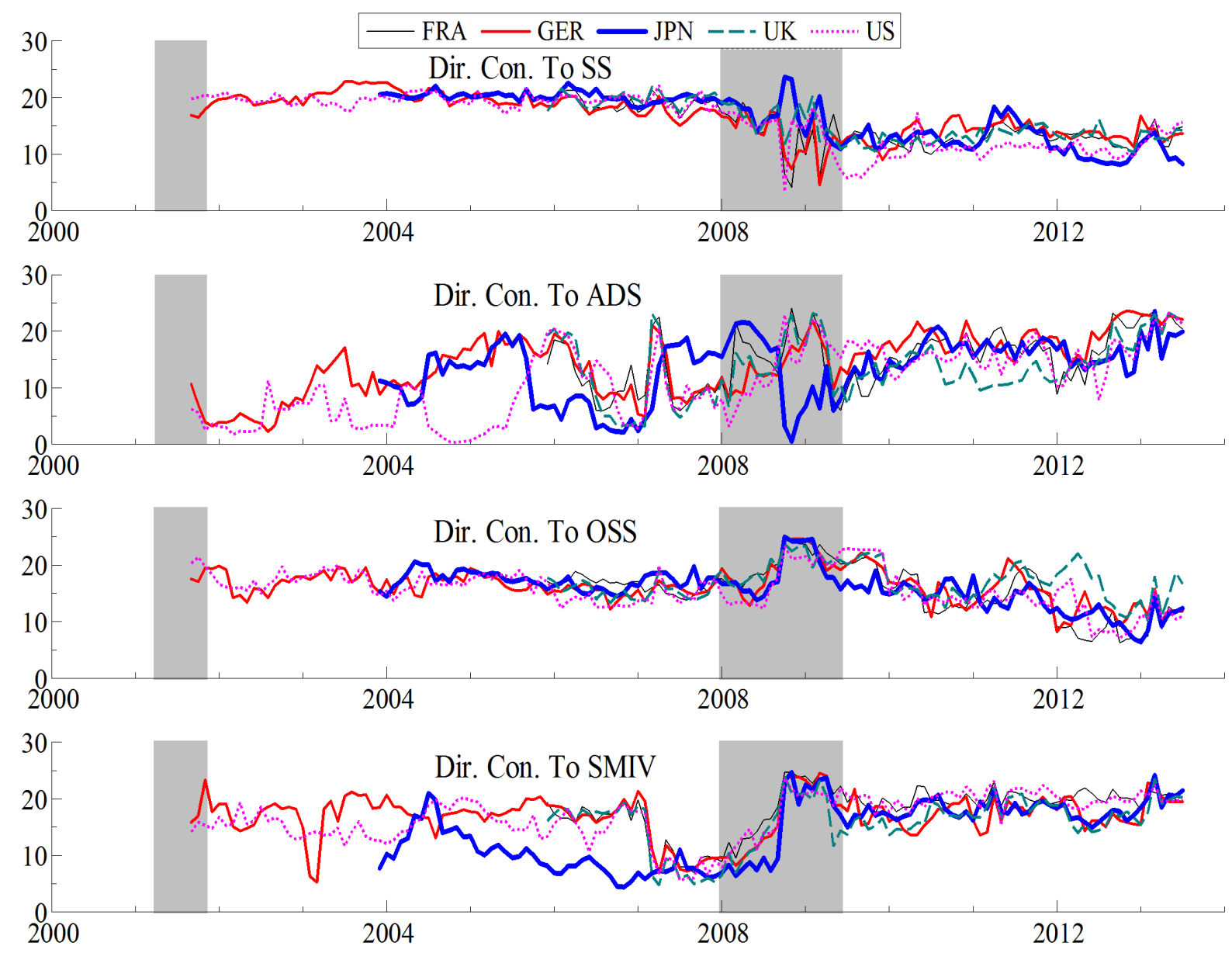